\title{
Emphysema then and now
}

\author{
WILLIAM M THURLBECK MB FRCPC \\ Department of Pathology, University of British Columbia, Vancouver, British Columbia
}

WM THURI.BECK. Emphysema then and now. Can Respir J 1994; 1(1):21-39.

The present definition of emphysema has three components: enlargement of airspaces, destruction of their walls and lack of fibrosis. Enlargement can be recognized by measuring the interalveolar wall distance or by comparing the airspaces under consideration with adjacent or distant normal lung. Most recently, destruction has been defined as disappearance or disturbance of the orderly appearance of the pulmonary acinus (gas exchanging tissue). Other authors have also suggested that destruction can be recognized by abnormal holes (fenestrae) in airspace walls or by the 'destructive index'. Fibrosis appears to be an integral part of centrilobular, distal acinar and irregular airspace enlargement. The presence of fibrosis should not preclude emphysema by definition. Emphysema should be recog. nized by practicable methods and should be measured in some way. Evidence is presented that abnormal elastic properties of the lung are not due to emphysema but reside in the surrounding lung; the altered elastic properties may be due to alterations in the glycoprotein matrix of the lung. Altered elastic properties are a relatively poor predictor of emphysema as generally defined and recognized. Computed tomography can recognize emphysema quite well, but appears to underestimate it and is not accurate in lungs with mild or no emphysema. Emphysema can be best diagnosed in life with an integrated approach using clinical data, radiological evidence of lung enlargement and the single breath diffusing capacity (transfer factor) for carbon monoxide. While knowledge of emphysema has dramatically increased in the past 30 years, much more remains to be done, and this requires new and more thorough approaches.

Key Words: Pulmonary emphysema, Clinicopathological correlations, Computed tomography. Definition, Elastic properties. Pathogenesis, Radiology

\section{I'emphysème d'hier et d'aujourd'hui}

RÉSUMÉ : La définition actuelle de l'emphysème comporte trois śléments, dilatation des espaces aériens, destruction des parois alvéolaires et absence de fibrose. On peut identifier la dilatation en mesurant la distance entre les parois interalvécolaires ou en comparant les espaces aériens à l'étude avec le poumon normal contigu ou distant. Dernièrement, la destruction a été définie comme la disparition ou la perturbation de l'aspect organisé de l'acinus pulmonaire (zone d'échanges gazeux). D'autres auteurs ont égale. ment suggéré d'identifier la destruction par les orifices anormaux (fenestration) visibles dans les parois alvéolaires ou par « l'index ke destruction ». La fibrose semble faire partie intégrante de la dilatation des espaces aériens centrolobulaires, acinaires distaux et irréguliers. La présence de fibrose ne devrait pas exclure la définition de l'emphysème. L'emphysème devrait être identifié par des méthodes applicables, et quantifíe d'une certaine manière. On apportera l'évidence que les caractéristiques élastiques anormales du poumon ne sont pas attribuables à l'emphysème mais plutôt au poumon contigu. La dégradation des caractéristiques élastiques pourrait être provoquée par une détérioration de la matrice glycoprotéinique du poumon. La dégradation des caractéristiques élastiques possèdent une faible valeur prédictive d'emphysème tel qu’il est généralement défini et reconnu. La tomodensitométrie permet assez bien d'identifier l'emphysème mais semble sous-estimer sa présence. De plus, cette méthode reste imprécise pour confirmer l'absence d'emphysème ou la présence d'un emphysème léger. Il reste qu'un diagnostic d'emphysème repose le plus souvent sur une approche globale faisant appel aux données cliniques, à l'évidence radiologique d'une hyperinflation pulmonaire et à la mesure du transfert du monoxyde de carbone par la méthode en apnée (facteur de transfert). Si les connaissances sur l'emphysème ont considérablement évolué au cours des 30 dernières annćes, il reste encore beaucoup à faire, et ceci requiert des approches nouvelles et plus minutieuses. 
$\mathrm{M}$

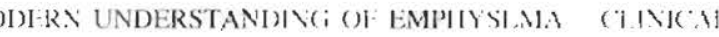
and pathological - began in 1957 when Leopold and Gough (1) published their classic paper on centrilobular emphysema and McLean (2) summarized his work in Australia. A lindmark meeting, the Ciba Foundation symposium (3). wats held in London in 1958 on what we would onw call chronic airflow obstruction (CAO) or chronic obstructive lung disease (then called chronic nonspecific lung disease). At the same time physiology had advanced so that several aspects of pulmonary function could be assessed in humans. Lung mechanics. until then thought of as an esoteric subject, became relevant to clinical investigation. The following 15 years saw an enormous outpouring of research involving chest physicians, pathologists, physiologists, epidemiologists and radiologists. As a result we now have a clearer understanding of the role of emphysema in severe chronic airlow obstruction. In contrast, reseatreh at tivity dectined in the past 15 years with emphasis on the pathophysiology of "small airways disease" and computed tomographic (CT') seimning of emphysema. Nonetheless, important observations and concepts emerged during this time.

It is illusory to thish that we have a complete knowledge of emphysema. IVe know the etiology, but not the pathogenesis. There are experimental models of emphysema, but their functional analogy to human disease is incomplete. We can recognize the severity of emphysema and the role it plays in patients with CAO during life with reasonable accuracy. Certain aspects of emphysema have never been clarified and others are confused. The cisy work has been done and more reliued investigations need to be perlormed.

This presentation deals with selected topics that I consider 10) be of interest and importarke. These are: the palloology of enphysema including definition. recognition, and measurement; altered elastic propertic in emphysema: the radiologicill changes of emphysema. including CT: and the dianowos of emphysema during life.

\section{DEFINITION, RECOGNITION AND MEASUREMENT OF EMPHYSEMA}

I) dinition, recognition and measurement of emphysema ine three interrelated topics. although this is not always appreciated. Definitions should le precise and they also involve theoreticil comcepls. ()rie therretical aspect (with practical implicitionss) is that a detimition may involve an 'on-off' concept of disease - either a subject has a disease or does not. Pickering (4) pointed out that arterial pressure was unimodally distributed and that defining arbitrary limits of normality had serious difficulties. He wrote: "the qualitative approach is still very much a habit of mind of all who have had a medical education ... and so the characteristics associated with a disease tent 10 ixe divided into normal and abnormal, physiological and pallhological, good and bad. Medicine in fact can count up (o two". As will be seen, the definition of emplyyscmit involves ilec "on-ofl" concept of disease. Recognition is a pratctical application of definition. Once recognized. emplysema should be quantiliced.

\section{Definition of emphysema}

The ('ihil symposium definition of emphysema was "il condition of the lung characterized by abnormal, permanent enlargement of the airspaces distal to the terminal bronchiole, accompanied by destruction of their walls" (3). Destruction was not defined but in most instances is obvious (Figures 1 to 4). In many ways this is not satisfactory since it is a simple subjective assessment. Thus, other definitions have been offered.

Alveolar fenestrae: In 1962, Boren (5) pointed out that discontinuíties in the alveolar wall could be seen using thick sections of lungs embedded in plastic. These discontinuities consisted of normal holes seen in nonemphysematous human and animal lungs (the pores of Kolnn) and also abnormal holes, described as fenestrae. Boren suggested that discontinuities larger than $20 \mu \mathrm{m}$ in greatest diameter should be considered abnormal and evidence of emphysema. No justilication was given for this size and his observation has been held in abeyance, although it was remarkably prescient. Nagai and others (6) have recently examined alveolar walls in a series of nonemphysematous lungs using scanning electron microscopy (SEM). They found that $94 \%$ of holes were 10 $\mu \mathrm{m}$ or less, and fewer than $0.2 \%$ of the holes were greater than $20 \mu \mathrm{m}$ in greatest diameter. Fenestrae of various sizes and shapes are readily visible in alveolar walls of emphysematous lungs (7), and holes of increased size and frequency also occur in alveolar walls in apparently nonemphysematous lungs between and distant from centrilobular emphysematous spaces (6). Fenestrae are visible in lungs of smokers (8). They are larger and more apparent near bronchioles where they have been associated with diminished expiratory how rates and loss of recoil (8). These correlations existeal only with holes proximal in the acinus and these molvilbly corresponded to boles in walls of centrilobular emplyscmat (8). SEM is, however, an unacceptably cumbersome method of defining emphysema.

Loss of alveolar surface area: Another approach to destruction was to measure the gas-exchanging (alveolar or internal) surface area of the lung. This had the great merit that it might be an objective method of recognizing destruction and that it might have at unimodal distribution as in hypertension (9). Unfortunitcly. even after adjusting for variations in lung volume duc to stature, alveolar surface area was insensitive. and mially lungs having obvious emphysema using nther criteria fell within the range of nonemphysematous lungs.

The destructive index: An innovation was the development of the 'destructive index' (DI) (10), and it was suggested that it may also be a useful way of defining destruction in emphysema. The DI has three components: airspaces with breaks in the alveolar wall (DIb); spaces lined by cuboidal epithelium (DIf); and classical emphysema (DIe) (not defined). The DI is obtained using microscopic examination of random histological sections of the lung. The authors (10) found that the mean DI was 16.8 (range 7.8 to 26.0) in the lungs of nonsmokers, and this was made up of breaks (90 to $100 \%$ of the lotal DI), histological changes ( 0 to $4 \%$ ), and classical empliysema (0 to $2 \%$ ). In the lungs of smokers, the mean DI was 
47.1 (range 9.8 to 76.4 ) and was made up of breaks (DIb, 59 to $86 \%$ of the total DI), histological changes (DIf, 0 to $15 \%$ ) and classical emphysema (DIe, 11 to 26\%). The DI correlated significantly with the forced expiratory volume $\left(\mathrm{FEV}_{1}\right)$ $(r=-0.43)$ and the recoil pressure of the lung at $90 \%$ total lung capacity (TLC) (PL90) ( $\mathrm{r}=-0.61$ ). The same group of workers (11) found that DIb was the same in upper and lower lobes, but DIe was higher in the upper lobes.

Saito et al (12), using lungs that had been used for post mortem measurements of pulmonary function, found that the Df was $5.8 \%$ in nonemphysematous lungs, $10.9 \%$ in mild emphysema (panel grade [PG] $0<\mathrm{PG} \leq 25$ ), and $55.7 \%$ in moderate and severe emphysema $(\mathrm{PG}>25)$. They found that histological emphysema accounted for $0 \%$ of the DI in the lungs without emphysema. They found that DI correlated significantly ( $r=0.53$ ) with the volume of the lung at a PL of $30 \mathrm{~cm} \mathrm{H} 2$ ) (V30), recoil pressure at $90 \%$ of V30 (PL90\% $\mathrm{V} 30)(\mathrm{r}=-0.49)$, and the shape $(\mathrm{K})$ of the pressure-volume curve $(r=0.48) . K$ is a constant in the equation

$$
\mathrm{V}=\mathrm{V}_{\max }-\mathrm{Be} \mathrm{e}^{-\mathrm{KP}}
$$

where $\mathrm{V}$ is the volume of the lung at pressure $\mathrm{P}, \mathrm{V}_{\max }$ is the theoretical volume of the lung at infinite transpulmonary pressure, and $B$ is the difference between $V_{\max }$ and the intercept of the fitted exponential on the volume axis. These correlations came about mostly by the inclusion of DIe in DI. Saito et al wrote: "we conclude that the DI is not of increased value in assessing emphysema and takes considerably more time than conventional measurements of emphysema". This conclusion is not completely fair. For example, Matsuba et al (13), using lungs from patients with moderately severe and severe emphysema, found that the DI increased rapidly up to PG 55 and then remained constant. When PG was below 55 the correlation between DI and emphysema was 0.84; above 55 , it was 0.01 . Thus, in severely emphysematous lungs, D1 consisted mostly of DIe. However, the lower the emphysemal score, the more useful DI is likely to be.

A more important criticism is that DI consists of several components, and it may not be obvious which component is of significance. Kuwano et al (14) found a correlation coefficient of about 0.70 between CT of the lung and DI. Not even the grealest advocate of CT would claim that it could recognize the component of DI due to DIb; obviously it was DI due to emphysema that was recognized. DI is still important. but it is Dlb that is of interest, although it is. of coursc. not emphysema.

Mean linear intercept and airspace wall per unit volume: Buth mean linear intercept $(\mathrm{Lm})$ and airspace wall per unit volume (AWUV) have been advocated as definitions of emphysema, but they reflect both airspace enlargement as well as loss of alveolar walls. They are reciprocally related, and as airspaces enlarge, the IWD increases and AWUV decreases. Lm will be discussed at greater length since it has been used more commonly, particularly in experimental emphysema.

The use of Lm stems from Dunnill's important paper in 1962 (15) and a subsequent one (16). He popularized the morphometric techniques pioneered by Weibel (17) in the human lung. The particular strengths of Dunnill's papers were their clarity and simplicity, enabling those with limited mathematical expertise to use morphometric techniques in the lung. He pointed out that the alveolar (gas exchanging) surface area could be calculated from the formula

$$
\mathrm{ISA}=4 \mathrm{~V} / \mathrm{Lm}
$$

where ISA was the alveolar surface area, $\mathrm{V}$ the volume of the lung and $\mathrm{Lm}$ the average interalveolar wall distance. For practical reasons, he measured $\mathrm{Lm}$ in tissue less than $2 \mathrm{~mm}$ in diameter, calling this 'parenchyma'. $\mathrm{V}$ in the equation is then substituted by $\mathrm{V} x \mathrm{~V}_{\text {vpar where }} \mathrm{V}_{\mathrm{v}}$ is the volume density (proportion) of parenchyma (par) defined by Dunnill as tissue less than $2 \mathrm{~mm}$ in size. He measured L.m on random histological sections, correcting for shrinkage during processing. Most importantly, Dunnill counted a transection through an alveolar wall (not alveolar surface) as ' $I$ ' and thus $L m$ represented the average distance between alveolar walls and not between epithelial surfaces. It is obviously affected by all tissue less than $2 \mathrm{~mm}$ in diameter and is not the average mean chord length of an alveolus. Mean chord length is also different from diameter, and the former represents the average transection distance when a line is placed repeatedly and randomly across the structure(s) in question. For example, the mean chord length, also the mean linear intercept, is $4 / 3 \mathrm{r}$ for a sphere (18).

In animal lungs, it is perhaps tsuall (the methodology is often not stated) to measure $\mathrm{Lm}$ in the entire lung, including parenchyma and nonparenchyma. Placing a brick in the middic of the lung will increase Lm it no attempt is made to uxclude its volume.

More correctly, one is interested in intercepts through each alveolar surface (two intercepts through an alveolar wall) to obtain gas exchanging surface area. Thus

$$
I S A=2 V / L m
$$

where $\mathrm{Lm}$ is the distance between aiveolar surfaces, and is derived from length of the test line $(L)$ divided by the alveoliar surface intercepts (i), or L/i. This $\mathrm{Lm}$ is more difficult 10 grasp since it represents both the interalveolar surface distance on both sides of an alveolar wall and the distance between alveolar surfaces across airspaces. Even if measured in true parenchyma (gas exchanging tissue and excluding airways, vessels, lobular septa, etc), it is a function of both alveolar and alveolar duct size. Alveolar walls are of finite thickness and comprise 10 to $15 \%$ of lung volume by light microscopy in animals $(19,20)$ so that $\mathrm{Lm}$ will be a function of them too. However, true mean chord length of alveoli and alveolar ducts can be measured quite simply (20). It follow's that if $\mathrm{Lm}$ is used to define or measure emphysema it should be described as unambiguously as possible, and it would ho better to refer to the average IWD rather than Lm.

IWD is affected by overexpansion of the lung, but the effect of this is quite small. For example, if lung volume doubles, its surface area will increase to the $2 / 3$ power (1.59 times), and linear measurements to the $1 / 3$ power $(1.26$ times). If one in five intercepts is destroyed by emphysema. 

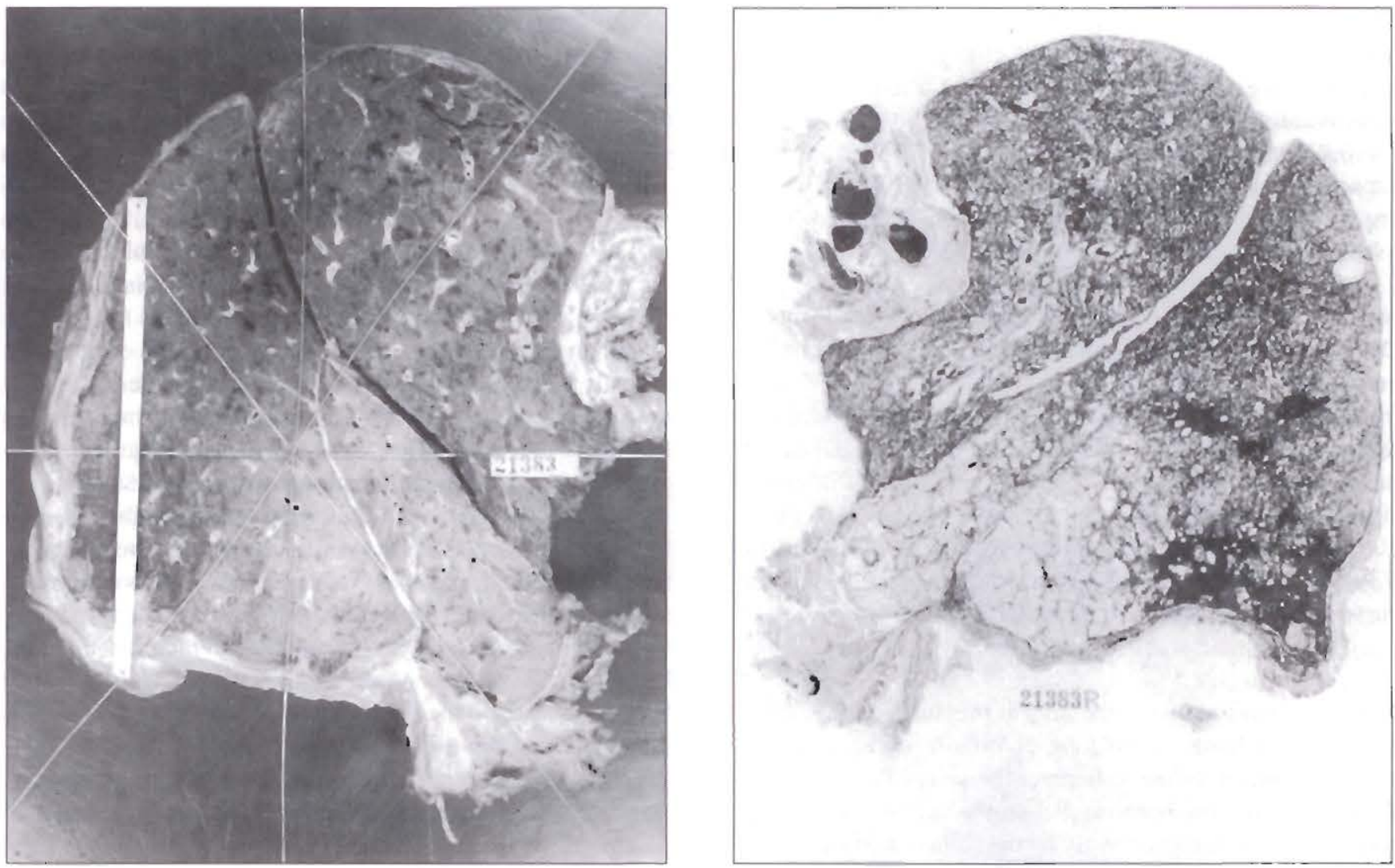

Figure 1) (Left) Slice of formalin fixed lung with emphysema apparent in the right middle lobe and anterior part of the lower lobe. (Right) Emphvsema is much more apparen in a paper-mounted whole lung section

IWD will increise $25 \%$. ln olker words a very large change in lun volume causes a riatively small change in IWD, and this is ilyproximated by a relatively small loss of alveolar walls.

The valuc of $|W|$ ) wals examined in emphysematous and normal lungs and it was found that obvious, even quite severe, emphysema could be present by gross and dissecting microscopic examination, yet IWD was within the limits lound in nonemphysematous lungs (9). IWD also increases with age in nonemphysematous lungs.

A rather more arbitrary definition of emphysema is an IVD of more than $350 \mu \mathrm{m}$. This definition will include mostly traditionally recognized emphysematous lungs but, as indicated, will exclude obviously emphysematous lungs as well as normal ones.

The measurement of AWUV, as performed, reflects airspace (alveoli, alveolar sacs and alveolar ducts) size and is not affected by intervening tissue such as alveolar cells, small blood vessels, etc. It has been suggested as a definition of emphysema and a precise range of AWUV is available in nonsmokers of both sexes and various ages (21). However, it is not a sensitive method of recognizing emphysema, since only $26 \%$ of smokers with an average age of 61 years (most of whom had lung resection for cancer) had AWUV values bolow the normal range (22). Smokers of this age can be expected to have an incidence of emphysema of $75 \%$ or more, and similar series of resected specimens have shown incidences of $100 \%$ (14), 87\% (23), 82\% (24), 73\% (25). and $75 \%$ (26). The incidence of emphysema was $49 \%$ in the series in which AWUV was also available (27). AWUV has little to recommend it as a definition of emphysema because of its insensitivity.

From the above, it follows that an increase in IWD or reduction in AWUV can be brought about by either airspace enlargement and/or alveolar wall destruction. For communication purposes an increased IWD or decreased AWUV should be reported as 'airspace enlargement with or without destruction' rather than 'emphysema'.

National Heart, Lung, and Blood Institute definition: Many years subsequent to the Ciba Foundation symposium, a committee of the National Heart, Lung, and Blood Institute met to define 'destruction' in emphysema. It agreed on the following: "Destruction in emphysema is defined as nonuniformity in the pattern of respiratory airspace enlargement so that the orderly appearance of the acinus and its components is disturbed and may be lost" (28). The committee rejected my suggestion that destruction meant that the acinus (the part of the lung distal to the terminal bronchiole) looked funny (peculiar), but that is all that the definition really means. However, they also added another restriction, feeling that airspace enlargement accompanied by fibrosis, such as is seen in honeycomb (endstage) lung, might be confused with emphysema. Their final definition was: "emphysema is defined as a condition of the lung characterized by abnomal. 

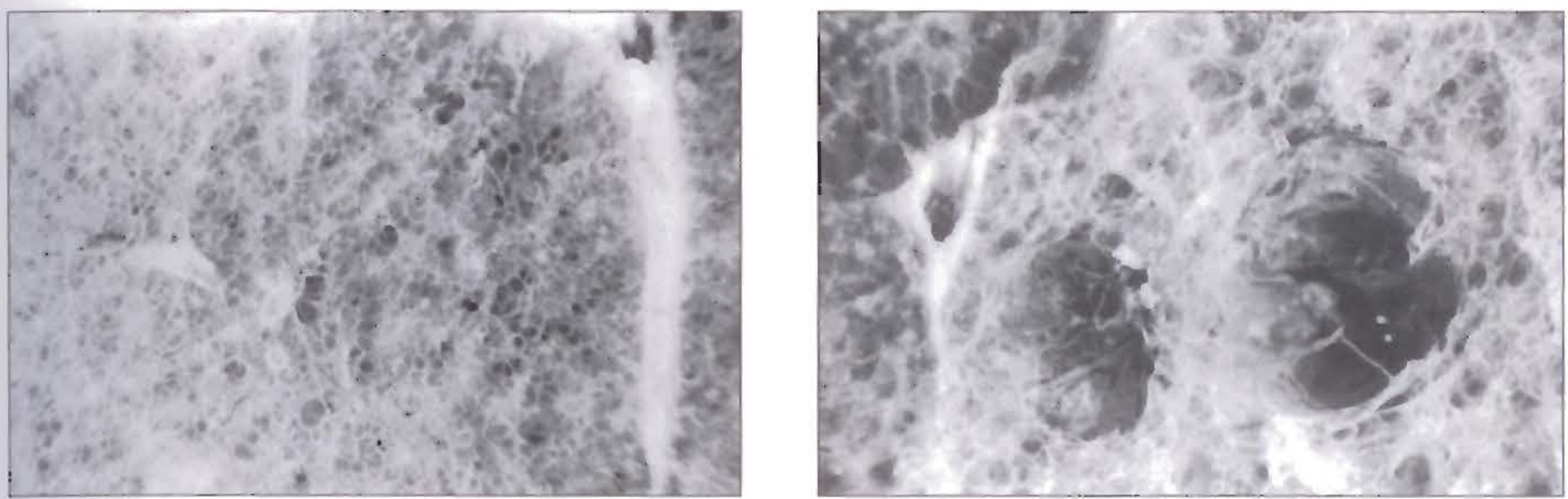

Fïgure 2) (Left) Dissecting microscope picture of formalin-fixed barium impregnated normal lung. (Right) Two centrilobular emphysematous (CLE) spaces are shown using the same technique as in lefi figure. Note abnormal airspaces in lungs surrounding CLE

permanent enlargement of airspaces distal to the terminal bronchiole, accompanied by destruction of their walls and without obvious fibrosis".

Unfortunately this definition negated the inflammatoryrepair hypothesis of the pathogenesis of emphysema (29), which indicates that the manifestations of inflammation of the lung are similar to those in other organs, in which inflammation is often followed by healing and fibrosis. Narrative comments and an illustration suggested that fibrosis and chrenic inflammation were an integral part of centrilobular (centriacinar) emphysema (30).

In 1993, Cardoso et al (31) showed that in the most common form of emphysema, centrilobular emphysema (CLE), collagen was increased morphometrically (it was also increased in distal acinar and irregular airspace enlargement. in the latter instance biochemically as well). This report suggests that the term "without obvious fibrosis" should be dropped from the NHLBI definition. The report also indicates that the "protease-antiprotease' hypothesis is an unduly simple approach to a complicated problem as has been recently emphasized (32). More importantly, it reminds readers (and investigators) that it is wrong to think of emphysema as a single disease, with one etiology, one pathogenesis and one functional consequence.

It thus seems that there is no real reason for replacing the original Ciba definition of emphysema, but it should be accompanied by a footnote stating that "destruction may be defined as the disorderly appearance of the acinus or by holes in the alveolar walls more than $20 \mathrm{~m}$ in diameter"

\section{Recognition of emphysema}

Gross and subgross recognition of emphysema: Emphysema was first properly recognized on paper-mounted whole lung (Gough-Wentworth) sections (Figure 1) (33), by gross examination of formalin inflated lungs (Figure 1), or by dissecting microscopic examination of barium impregnated. formalin inflated slices of lung (34). The latter technique gives particularly pleasing results (Figure 2 ), but subsequent studies have shown that if Bouin's fixation is used, equally satisfactory results can be obtained (23) and the messiness of barium sulphate impregnation can be obviated. Papermounted whole lung sections are expensive and very few institutions make them any longer. Therefore, Nagai et al (35) developed a method of recognizing parenchymal destruction using histological sections of the lung. This method makes the use of whole lung sections unnecessary and is related to conventional assessments of emphysema and abnormalities of pulmonary function tests (35).

Loss of alveolar attachments: Loss of alveolar attachments to bronchioles (radial traction) has long been considered to be associated with aiflow obstruction, particularly on expiration (36.37). Although loss of alveolar altachments was nes proposed as a definition of emphysema, it may be one way of recognizing emphysema. It must, however, be regarded as evidence of parenchymal destruction. One study concluded that "loss of alveolar attachments represents an early stage in the destruction of lung parenchyma" (38). Others $(39,40)$ implied that loss of alveolar wall attachments could be used to estimate the presence and degree of airspace destruction. Yet others have shown a relationship between an increase in distance between alveolar attachments and the percentage of alveoli destroyed (4I) or found a correlation between diminished attachments and emphysema (42,43). It thus seems likely that loss of alveolar attachments is a manifestation of emphysema. But of what sort of emphysema? In very severe emphysema, probably of any sort, peripheral airways are obviously irregular in shape and poorly supported (30). In mild emphysema specific types of emphysema may be involved. Since alveolar attachments have been measured around membranous bronchioles, destruction in this region must be distal in the acinus. It seems unlikely to bi purely or dominantly distal acinar emphysema since this does not ap?. pear to have been recorded. It is more likely that respiratory bronchioles also have loss of attachments placing the lesion in the central (more accurately the proximal) part of the acinus, and hence CLE may account for loss of attachments. Perhaps loss of attachments to respiratory bronchioles is called CLE. In other instances. the loss of attachunents may he more widespread as might occur in panacinar emphysema (P.E). 

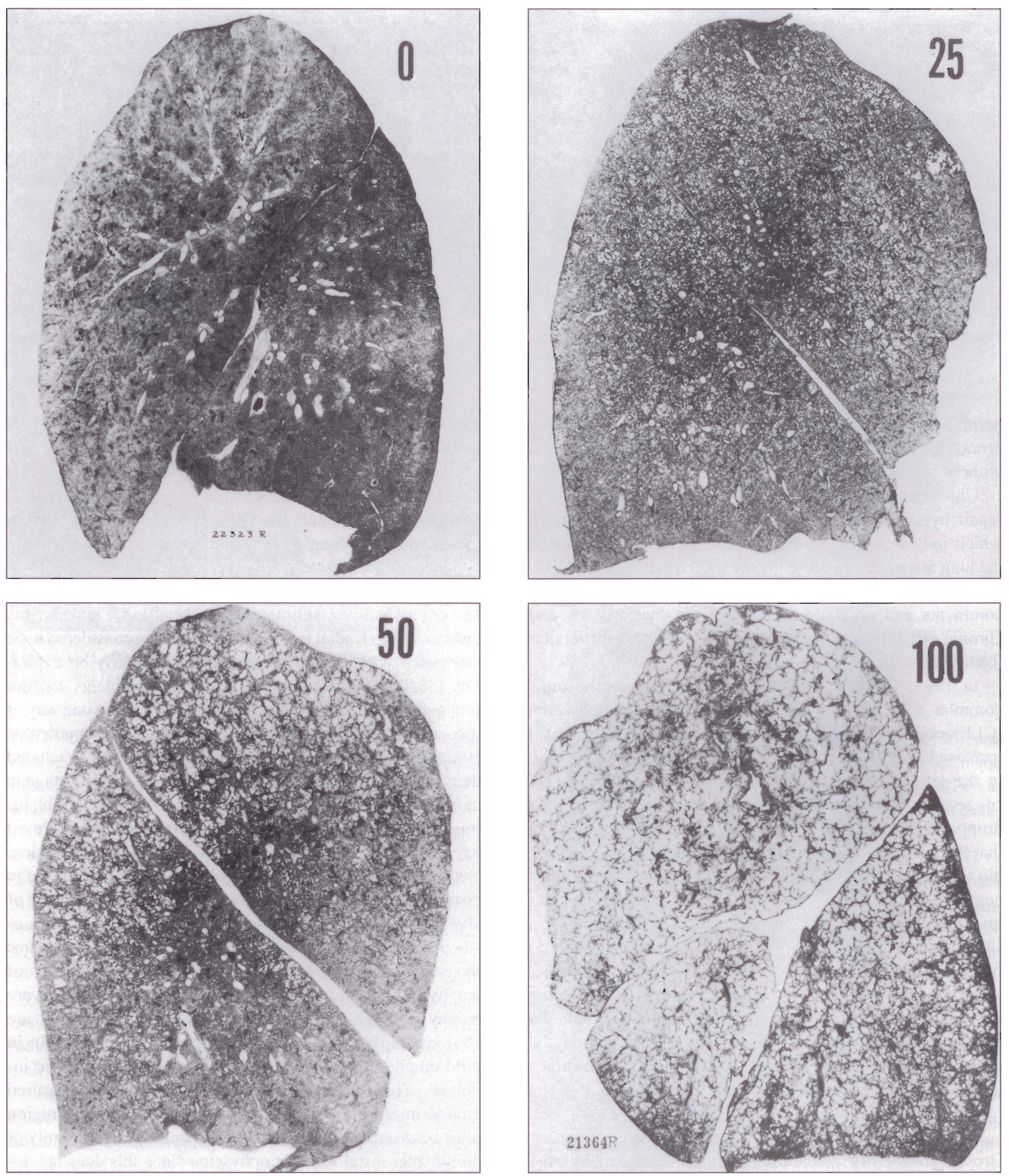

Figure 3) Paper-mounted whole-lung sections showing panel grade (PG) O, PG 25, PG 50 and PG 100

Airflow obstruction in emphysema: This, of course, raises the whole complicated issue of airflow obstruction in emphysema. There is abundant evidence that airflow is obstructed in emphysema whether severe $(43,44)$ or mild $(24-26,41$, $42,46-48)$. In many instances the obstruction is mainly due to cigarette-associated bronchiolar disease. In as many others, emphysema plays a more important role, and this may be due to loss of elastic recoil (reviewed later) or to bronchiolar disease associated with emphysema. These latter lesions include bronchiolar narrowing and deformity $(45,49)$ and in- 

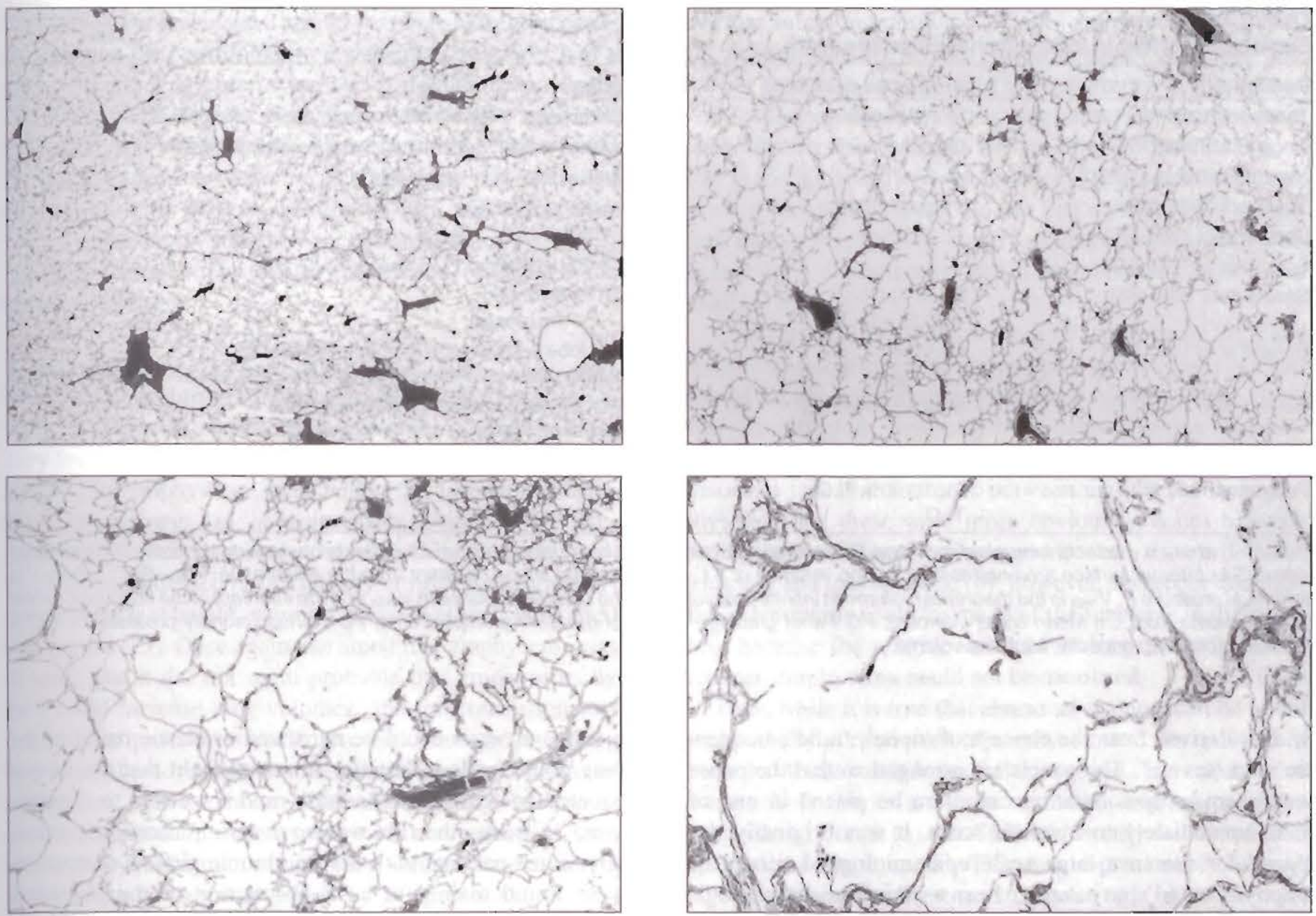

Figure 4) Section grading method showing standard panels for grade 0 (top left). grade 3 (top right). grade 6 (bottom left) and grade 9 (bottom right). Dr Atsushi Nagai kindly provided the pictures

clude narrowing of stenotic bronchioles (44) in severe emphysema. In less severe emphysema, manifested most obviously by diminished alveolar attachments, there may be bronchiolar narrowing $(38,42)$ or 'ellipticality' (deformity) (50) with associated airflow obstruction $(41,42,51)$. On closer examination loss of alveolar attachments may turn out to be CLE or PLE. It should be noted that loss of attachments may be associated with loss of recoil $(38.42)$ and is not always associated with airflow obstruction (38). In any event, loss of alveolar attachment seems to be a curiously indirect way of recognizing emphysema.

\section{Measurement of emphysema}

Traditionally, measurements may be regarded as either objective or subjective, the latter being measurements that may be affected by the opinions of the observer. All measurements of emphysema are subjective since a decision has to be made whether a part of the lung is emphysematous. Furthermore, besides subjectivity or objectivity, there are two different ways in which emphysema can be measured (46). The extent of the lung involved by emphysema can be measured. or the severity of the emphysema can be assessed. The difference between the two is important since PLE and CLE affect the extent of involvement differently.
Measurement of extent: In PLE the whole acinus is involved so that the extent is large; in CLE the proximal portion of the acinus is only or especially involved so that the extent is relatively small (52). This point has been well made by Miller et al (23) using surgically excised lungs. They point out that bullae showed severe emphysema that was localized in extent, and that PL.E could be mild yet involve large zones of the lung. It is also true that measurements of extent are less reproducible between observers than those of severity (53), and in that study the variation of the extent of involvement was extreme. For example, estimates made by the expert (b)ervers varied from $01085 \%$ and from 5 to $100 \%$ in two itungs.

The extent of emphysema has been measured in whole lung slices (54), or the lung can be divided into smaller units such as parts of lobes (55), $1 \mathrm{~cm}$ squares (56) or points (15,57).

Measurement of severity of emphysema: Initial measurements of severity included the entire lung or slices of lung (58), Iobes (3), bronchopulmonary segments (59) or tenths (60). A widely used measurement of the severity of emphysema is the 'panel grading' (PG) method (58). It is extremely simple and consists of matching paper-mounted whole lung sections to a panel of pictures scored from 0 to 100 (Figure 


\section{TABLE 1}

\section{Elastic properties in mild emphysema (see text)}

\begin{tabular}{|c|c|c|}
\hline Reference & Properties assessed & Findings \\
\hline Thurlbeck 1967 (9) & Morphology & Lm increased, ISA 5 normal in emphysema $1-5$ ( $\max 30)$ \\
\hline Hogg et al $1969(73)$ & Compliance & Decrease in CLE spaces, increase in lung as a whole \\
\hline Niewoehner et al 1975 (74) & $\alpha_{1}$ & Decrease in $1-10 \%$ emphysema \\
\hline Thurlbeck 1979 (75) & VL post mortem & Increase in $P G 1-5$ \\
\hline Berend et al $1980(76)$ & PL.VL & PG 1-5 'trends' \\
\hline Berend et al $1980(77)$ & & PG 6-20 decreased PL, increased VL \\
\hline Silvers et al $1980(65)$ & $\begin{array}{l}\text { PL \% TLC } \\
\% \text { TLC }\end{array}$ & $\begin{array}{l}\text { PGI 1-5; Reduced } \\
\text { Increased }\end{array}$ \\
\hline Berend et al $1981(78)$ & PL 50-90 & $\begin{array}{l}\text { Upper lobe = lower lobe in nonemphysema } \\
\text { Lobe with more severe emphysema }>\text { lobe with less severe emphysema }\end{array}$ \\
\hline Berend et al $1981(79)$ & Shape constant $K$ & $\begin{array}{l}\text { Nonemphysema upper lobe }>\text { lower lobe } \\
\text { Emphysema; more severe }=\text { less severe }\end{array}$ \\
\hline Saetta et al $1985(10)$ & PL $90 \%$ TLC & Correlation DI $r=0.61$ \\
\hline Petty et al 1987 (62) & $\begin{array}{l}\text { PL } 70-90 \% \text { TLC } \\
\text { TLC }\end{array}$ & 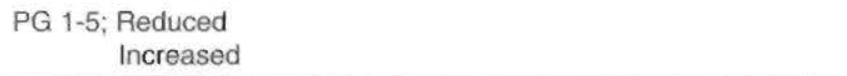 \\
\hline
\end{tabular}

$P=\alpha_{1} e^{\alpha_{2} V}$ where $\alpha$; reflects lung elastance and $P$ is transpuimonary pressure at fung volume; CLE Centrilobular emphysema; DI Destructive index; ISAs Internal surface area normalized to lung volumes of $5 L ; K$ Exponential shape constant from the equation $V=V$ max $-B e^{-K P}$ where $V$ is volume at pressure $P, V_{\max }$ is the theoretical volume at infinite pressure, $B$ is the difference between $V_{\text {max }}$ and the intercept of the fitted exponential on the volume axis; $L m$ Mean linear intercept; PG Panel grading method of measuring emphysema; PL Transpulmonary pressure; \% TLC \% predicted total lung capacity; VL Lung volume

3). It is derived from the concept of 'none', 'mild', 'moderate' and 'severe'. The panels are arranged so that the paper section under consideration can often be placed in one of them immediately to obtain a score. It was originally designed for use in a large scale epidemiological survey of emphysema (61) but has since been used in clinicopathological studies of emphysema (41,62-66). It was also designed for use with paper-mounted whole lung sections but has been used with slices of formalin distended lung $(41,67,68)$. It has also been used with formalin fixed sections of single lobes, extrapolating from them to the whole lung (69). It is surprising that this is possible, especially from the lower lobe. The grading panels below 20 have no or 'trace' emphysema in the lower lobes, so that in this range it should be impossible to predict the upper lobe (and whole lung score) other than for 0 . This use has been criticized (23). It should be noted that the scale of 0 to 100 is nonparametric and certainly not meant to be a percentage.

As indicated, the 'section method' has been used to recogriize emphysema and also can be used to measure it (35). This method is easy to use (Figure 4) and is recommended when paper-mounted whole lung sections are not available.

IWD, ISA and AWUV are objective measurements that may be used to assess severity. Increase in IWD and decrease in ISA parallel subjective assessments of severity (9). CLE is likely to produce smaller changes in these measurements than PLE so that they may lack accuracy of measuring, as well as sensitivity, in defining emphysema.

\section{LOSS OF ELASTICITY IN EMPHYSEMA}

Ever since Christie's discovery (70) that emphysematous lungs showed loss of elastic recoil, it has been regarded as the functional hallmark of emphysema. Macklem (71) pointed out that airflow could be limited by only one of two mecha- nisms - airways could be narrowed or elastic recoil of the lung could be lost. Initially it was thought that the former equated to 'chronic bronchitis' and the latter to 'emphysema'. Clearly, the first was an oversimplification, particularly since patients with severe chronic airflow obstruction were found mainly to have obstruction of the peripheral airways (72). Equating emphysema with loss of recoil is no less of an oversimplification. Indeed, obstruction to airflow should be regarded as complex, with many different lesions in various parts of the lung contributing to flow limitation (45); these occur together in variable ways (49).

\section{Loss of elasticity in mild emphysema and its possible causes}

The doughnut and the hole - the convential glazed doughnut: The first issue is whether loss of elasticity is in fact due to emphysema. Several papers have appeared that have shown loss of elasticity, real or inferred, in mildly emphysematous lungs (Table 1). While measuring average IWD and ISA, it became apparent that the former was abnormal in mildly emphysematous lungs, whereas the latter was normal, even when corrected for the effect of intersubject size difference (9). The former was in itself surprising in that the extent of emphysema was so small that it seemed unlikely that it could affect IWD. Also, no loss of ISA implied that lung volume increased in mildly emphysematous lungs since ISA is directly related to lung volume and inversely related to IWD. This leads to what is colloquially referred to as the 'doughnut and not the hole' hypothesis, namely that loss of elasticity is due to tissue between emphysema, rather than the emphysematous spaces themselves, and leads to an increase in lung volume.

Hogg et al (73) measured the pressure-volume characteristics of centrilobular emphysematous spaces in excised 
lungs and found that in the 0 and $20 \mathrm{~cm}$ range of transpulmonary pressure, the centrilobular emphysematous spaces had a greater resting length and were less compliant than normal lung tissue, ie, the spaces were disproportionately large at 0 transpulmonary pressure and expanded little between 0 and $20 \mathrm{~cm}$ transpulmonary pressure. A single lung was examined that showed mild PLE in addition to CLE and a pressurevolume relationship characteristic of emphysema.

Using excised lungs, Niewoehner et all (74) filled the empirical equation

$$
P=u_{1} \cdot e^{\alpha_{2} V}
$$

where $V$ is the volume of the lung at pressure $P, \alpha_{1}$ expresses the elastic behaviour of the lung and $\mathrm{a} 2$ the size of the lung. They found that five of nine lungs with 1 to $10 \%$ of the lung involved by emphysema were below the limits in nonemphysematous lungs. al is reciprocally related to K. Subsequently, I found that volumes of lungs fully distended with formalin, and assessed radiologically at full inspiration, corrected for patient height, were increased in trivial (PG 1 to 5 ) emphysema (75). Once again, the amount of emphysema was so small that it did not seem probable that emphysema by itself could increase lung volumes, and the conclusion was reached that "probably the scleroproteins throughout the lung have been altered, suggesting that the destructive lesions of emphysema and maximum lung distensibility have proceeded independently". Loss of recoil and increased total lung capacity (maximum excised lung volume) were found in patients with trivial emphysema by Silvers et al (65) and Petty et al (62); loss of recoil was also found in patients with normal $\mathrm{Lm}$ and diminished alveolar attachments (38), these patients presumably corresponding to the minimal emphysema group.

Berend et al $(75,76)$ re-examined maximum lung V30 in air filled lungs and $25 \mathrm{~cm} \mathrm{H} 2 \mathrm{O}$ in formalin inflated lungs, as well as pressure-volume curves. They found 'trends' for lung volumes to be higher and recoil pressure to be less in those with trivial emphysema (PG 1 to 5) and these changes became significant in mild emphysema (PG 6 to 25). They then compared lobar PV curves and found that transpulmonary pressures at 50 to $90 \%$ of $\mathrm{V} 30$ were similar in upper and lower lobes; however, when the more severely emphysematous lobe (usually the upper) was compared with the less emphysematous lobe, recoil pressure was greater in the lobe with the more severe emphysema (78). Conversely, when they fitted an exponential to the lobar pressure-volume curves (79) they found that the shape constant $\mathrm{K}$ was higher in the upper lobe than the lower in nonemphysematous lungs, but when less emphysematous lobes were compared with more emphysematous ones, the shape constants were the same.

From these studies it seems probable that lungs with trivial emphysema, and certainly lungs with mild emphysema, have lost recoil. Perhaps the lobar studies are the most convincing ones to support the 'doughnut and not the hole' hypothesis. The nature of the doughnut - morphological changes in the tissue between emphysema: The question arises whether subtle morphologic changes are present. For example, does the DI due to DIb represent these? Adequate data are not presently available but the occurrence of diminished PL90 with increased DI (10) is suggestive. However, it is not clear whether this is due to DIe or DIb. We have examined $\mathrm{DIb}$ in the apparently normal part of emphysematous lungs, terming these DI'd. We could not find a statistically significant increase in DI'd in mildly emphysematous lungs, allhough DI'd was almost doubled (the number of cases was small) (12).

Cosio et al (8) examined the lungs of smokers by SEM and found increased fenestrae in the 'near areas' (the proximal part of the acinus) and these correlated with the PL90. However, as indicated, these may have been fenestrae in centrilobular emphysematous spaces. Nagai et al (6) also found abnormal fenestrae in zones between and distant from emphysema, and these were more obvious in zones between emphysematous spaces. Correlations were shown between fenestrae and loss of recoil (6); however, no proper quantitative assessments could be made of the fenestrae in the entire lung because the relative volumes of lung away from and between emphysema could not be measured.

Thus, while it is true that abnormal features can be found in apparently normal parts of emphysematous lungs, it is not clear that these cause loss of elastic recoil. The attention of readers is drawn to a comment in the original paper by l.eopold and Gough (1) that CLE was usually associated with 'generalized emphysema'. This would presumably now be called panacinar emphysema. In other words in an uncertain proportion of cases, the lung tissue distal to CLE is attenuated and the airspaces increased in dimension (24). This may be the doughnut and it is easily measurable.

A different kind of doughnut, or the chocolate doughnut: There may be more than one kind of doughnut, and the above discussion refers to series (with the exception of Hogg et al [73]) in which no distinction was made between CLE and PLE. Most of the cases were probably CLE. The terms 'altered elastic properties' and 'loss of recoil' of the lung have been used previously and will be used subsequently, although these terms are rather imprecise. Macklem and Eidelman (80) have indicated some of the complexities of pressure-volume curves and have theorized that increased resting length in emphysema is characterized by increased TLC, and a decrease in distensibility is characterized by an increase in elastance (or expressed in the more usual way, increased distensibility is characterized by increased specific compliance). It is also true that measurements of elastic properties will only represent the lung between residual volume (RV) and TLC and do not give any information about the lung behínd closed airways.

In a subsequent paper, Eidelman et al (81) review the literature and indicate that pressure-volume curves in patients with clinical emphysema are heterogenous, and that reported compliance studies have shown that patients may have compliance values that were often decreased and could be normal or increased. They also compared patients with and without $\alpha_{1}$ antitrypsin (AT) deficiency and found that those patients 


\section{TABLE 2}

Comparisons of characteristics of morphological centrilobular emphysema and panacinar emphysema (82)

\begin{tabular}{lcc}
\hline & $\begin{array}{c}\text { Centrilobular } \\
\text { emphysema } \\
(\mathbf{n}=18)\end{array}$ & $\begin{array}{c}\text { Panacinar } \\
\text { emphysema } \\
(\mathrm{n}=16)\end{array}$ \\
\hline Csp (L/cm $\left.\mathrm{H}_{2} \mathrm{O} / \mathrm{FRC}\right)$ & 0.059 & 0.102 \\
$\mathrm{~K}(\%$ pred) & 99 & 134 \\
PL90 (\% pred) & 77 & 77 \\
TLC (\% pred) & 109 & 109 \\
P400 & 48.9 & 31.2 \\
Muscle in bronchioles $(\%$ of $\max )$ & 53 & 30 \\
r SAD and $\mathrm{FEV} /$ FVC & -0.69 & 0.29 \\
r K\% and FEV $/$ FVC & 0.08 & -0.72 \\
\hline
\end{tabular}

Csp Specific compliance; FEV, Forced expiratory volume; FRC Functional reserve capacity; FVC Forced vital capacity; $K$ Shape constant $K$ (see Table 1); P400\% bronchioles < 409um; PL90 transpulmonary pressure at $90 \%$ total lung capacity; SAD Small airway disease score; TLC Total lung capacity

without $\alpha_{1}$ AT deficiency and with diminished PL90 behaved in a similar, but not identical, waly to $\alpha_{1}$ AT deficient patients, whereas patients without $\alpha_{1}$ AT deficiency and normal PL90 developed more severe airflow limitation not related to recoil loss. These results suggest different effects of CLE and PLE. The inability to make a clear-cut distinction of the curves of non- $\alpha_{1}$ AT deficient subjects into two groups is in keeping with the well known observation that patients with severe anatomical emphysema usually have mixtures of CLE and PLE (30). It should be noted that, depending on the way the exponential is fitted to the pressure-volume curve, $\mathrm{K}$ may not accurately reflect compliance alterations in living subjects. The pressure-volume curve is often nearly linear at lower levels where compliance is measured and this cannot fit an exponential. If a program is written to maximize the fit and obtain the highest possible $r^{2}$ values, then the upper part of the curve, ie, 70 to $90 \%$ of TLC, will have a dominant effect and, as indicated, the pressure-volume curve behind closed airways cannot be measured.

Kim and others (82) compared 18 patients with pure or clearly dominant CLE with 16 patients with pure or dominant PLE using microscopic examination of presumably randomly taken blocks of lung tissue. Surgically resected lungs (in 24 of the 34 cases lobes only were examined) were used; thus the patients were not likely to have severe CAO and, by inference, probably had relatively mild emphysema. It is surprising that such a large number of patients with separate forms of emphysema could be found from what is probably a small total number of cases. The two groups of patients were of the same age and with the same smoking history, and had pulmonary function tests and IWD that were not significantly different. The patients with PLE had higher compliance and $\mathrm{K}$ than patients with CLE (Table 2), and increasing AWD was associated with an increase in compliance and diminished P90 in PLE. What is surprising is that patients with PLE did not have increased TLC. Patients with CLE had significantly increased muscle in peripheral airways and a higher proportion of airways less than $400 \mu \mathrm{m}$ in diameter. Decreased flow was related to loss of elasticity and not to airway abnormalities in PLE; the reverse was true of CLE (Table 2). Thus, in PLE altered elastic properties appear to lie in the emphysematous lung, a conclusion in keeping with simple histological examination of lungs. It seems unlikely that anything other than a mixture of elastic propertics would be found in the lungs of patients with severe CAO.

Loss of elastic recoil without emphysema - the jelly doughnut: Finally, it may not even be necessary for the doughnut to have a hole. This was first suggested by Berend ct al (25), who wrote that "changes in elastic recoil may occur in smokers without emphysema" (found in one of five such patients). Osborne et al (83) studied 44 lobes resected for cancer and divided their patients into four groups (Table 3): first, those with little or no emphysema and normal K; second, those with little or no emphysema and high $\mathrm{K}$; third, those with 'high' emphysema score and normal $\mathrm{K}$; and fourth, those with 'high' emphysema score and high $\mathrm{K}$. This study has several possible errors, and assumptions had to be made to correct for these possible errors: emphysema was diagnosed from lobes, and projections had to be made to the whole lungs; the lobes were badly underinflated (by a factor of 3.5) and corrections were made by assumptions of lobar volumes in life (that add up to $105 \%$ TLC) together with isotropic expansion of all lobes; IWD is not precisely described, and is measured in a few nonrandom sections per case that avoided emphysema.

Nonetheless, it is clear that $\mathrm{K}$ can be increased in lungs with little or no emphysema; this is also true when the single nonsmoker is excluded from group 2 (low emphysema, high $\mathrm{K}$ ) and when the patients with no emphysema are compared with those with emphysema in that group. Expressed in another way, three of 12 smokers without emphysema in one study and three of 16 in another had $\mathrm{K}$ values greater than two standard deviations above the mean $(48,83)$. Thus elastic properties may be obviously abnormal in smoking patients with little or no emphysema, and these patients may also have an increased IWD (83). This observation is in keeping with the theoretical analysis made by Laros and Kuyper (84). They pointed out that glycosoaminoglycans, glycoproteins and proteoglycans may play a key role in cementing the elastin and collagen fibres that traverse, and are part of, the extracellular matrix. These authors provide a dramatic illustration of a collapsed scaffold to illustrate how a framework is more easily disrupted by losing connections between components than by disrupting the components (representing elastin and collagen fibres in the lung).

Thus, it may be more reasonable to think of cigarette smoke as having a ubiquitous damaging role in the lung: chronic bronchitis, which is a relatively early effect on central airways; bronchiolar inflammation, which results in narrowing and is a particularly important cause of llow obstruction in relatively mild chronic airflow obstruction; emphysema, which is a result of parenchymal inflammation; and disturbance of the matrix of the lung, which alters elastic properties. Each of these may occur separately, but more 
TABLE 3

Groups of patients reported by Osborne et al (83)

\begin{tabular}{lcccc}
\hline Emphysema category & Number of patients & \multicolumn{2}{c}{} & \multicolumn{2}{c}{ Emphysema score (PG) } \\
\hline 1. Little or none & 12 & Within 2 SD & Mean & Comment \\
2. Little or none & 12 & $>2$ SD & 2 & Four with E, highest 10 \\
3. High & 10 & Within 2 SD & 2 & Six with E, highest 8 \\
4. High & 10 & $>2$ SD & 26 & All with E, nine PG 15-27 \\
\hline
\end{tabular}

E Emphysema; K Exponential shape constant; PG Panel grade; SD standard deviation

often will occur together in various combinations because of the common etiological agent. A linal comment is in order. Studies of surgically resected lungs do not reflect 'early' flow obstruction and 'early' emphysema, and studies of autopsy lungs do not reflect 'late' flow obstruction and 'late' emphysema. Patients are much the same age and have much the same smoking history. Surgically resected lungs more probahly represent lungs that are relatively resistant to cigarette smoke, and the autopsy cases represent lungs that are more sensitive.

\section{Alteration of elastic properties of the lung as a predictor of emphysema}

This topic is difticult to analyze in reported studies since different assessments have been made of elastic properties of the lung; emphysema has been measured in different ways; different sources of lungs have been used (lungs resected at surgery, lungs at autopsy from patients examined during life or lungs examined by post mortem function tests); and varying degrees of emphysema have been present. Since it atppears that elastic properties are complex and may be altered in mildly emphysematous lungs, and indeed in nonemphysematous lungs, it seems unlikely that any single test of elastic properties will predict accurately the amount of emphysema in the lungs.

Studies in excised human lungs: It is hard to analyze earlicr work in detail since the results are presented Iargely in a narrative way. McIlroy and Christie (85), Pratt et al (37) and Ishikawa et al (86) found that compliance was increased in emphysematous lungs together with a decrease in recoil pressure of the lung. Using the equation referred to previously, Niewoehner et al (74) found a correlation of +0.90 between $\alpha .1$ and the surface to volume ratio of the lung. Silvers et al (65) and Berend et al (77) found that PL70-PL90 was reduced more in mild and moderate emphysema than trivial emphysema; the former authors found that $\alpha_{1}$, which is reciprocally related to $\mathrm{K}$, was further decreased in mild to moderate emphysema. Both groups assessed emphysema using the PG method.

Closer relationships between emphysema and pressurevolume curves were found in excised human lungs by Greaves and Colebatch (63) who found a correlation between $\mathrm{K}$ and $\mathrm{PG}$ assessment of emphysema ( $\mathrm{r}=0.73$ ) and an even higher correlation $(+0.90)$ with IWD. The latter should be expected since IWD and $\mathrm{K}$ are well correlated in a variety of normal mammalian lungs of various sizes and different IWI)
(87). Berend and Thurlbeck (66) also found correlations between $\mathrm{K}$ and mild emphysema (PG) but much lower values $(+0.39$ to +0.43$)$. It should be noted that Berend (76) found larger volumes and lower pressures at all lung volumen in excised lungs compared with those predicted in life.

Pressure-volume curves in vivo: Pressure-volume curves are performed most commonly on patients before surgery. The advantage is that the interval between physiological assessment and morphological examination is short. The disadvantage is that usually only one lobe is removed and therefore extrapolation to the whole lung is necessary, and that disease is present that may affect lung structure or function. Post mortem studies have the disadvantage that the interval between functional assessment and pathological assessment may be large. This was obviated in the National Institutes of Health Intermittent Positive Pressure Breathing trial (44).

The earliest studies are not easy to interpret but indicate that recoil pressures are reduced in emphysematous lungs (88-90). Berend et al (25) examined resected lobes of 21 smokers and one nonsmoker and found a correlation between emphysema and $K$ and compliance ( $r=0.49$ ). Pare et al (48) analyzed 55 patients and found that emphysema score (PG) correlated with $\mathrm{K}(\mathrm{r}=0.35)$ and the maximum transpulmonary pressure $\left(\mathrm{P}_{\max }\right)(\mathrm{r}=-0.34)$. Subsequently, as part of another study of 32 patients used primarily for CT pathological studies (26), no correlation was found between emphysema and $\mathrm{K}$ or $\mathrm{P}_{\max }$. In a study of 173 patients no correlation was subsequently found between emphysema and $\mathrm{K}$ (83). Lm in a subgroup of cases was, however, related to $K(r=0.37)$ and Pmax ( $r=-0.39$ ). West et al (44) studied auropsied lungs of patients who had pulmonary function tests during life and found that $\mathrm{K}$ was not related to the $\mathrm{PG}$ score of emphysema, but that P90 was $\left(r_{s}=-0.41\right)$ and $K$ was related to $\mathrm{Lm}$ $\left(r_{s}=0.44\right)$. The diffusing capacity for carbon monoxide $\left(D_{C O}\right)$ was compared with elastic properties to predict emphysema in surgical specimens (47). These authors found that DCO and the ratio of DCo to alveolar volume (DCo/VA) had correlations ( $r=-0.53$ and -0.55 , respectively) with emphysema (PG) and these were higher than $\mathrm{P}_{\max }(\mathrm{r}=-0.42)$ and $\mathrm{P} 90$ $(\mathrm{r}=-0.43)$. They concluded the DCO is "a better predictor of macroscopic emphysema than are measurements from the pressure-volume curve". In summary, elastic properties of the lung are not well enough related to emphysema to be used as predictors of emphysema, but no systematic approach has becrl made to interpret alterations in elastic properties. 


\section{EMPHYSEMA AND RADIOLOGY Conventional radiology}

The accuracy of the radiological diagnosis of emplyysemal has been a matter of some dispute, and the literature up to 1975 has been reviewed elsewhere (30). Laws and Heard (9) ). without giving data, stated that reduction in the number ind calibre of peripheral pulmonary vessels was the most reliable radiological sign to predict emphysema post mortem. They felt that most examples of severe emphysema could be recognized radiologically but mild emphysema was undetectable. They thought that overinflation of the lung was not a reliable sign of severe empliysema, which could be present in the absence of overinflation. Reid and Millard (92) used a combination of signs - overinflation, small pulmonary vessels and heart, and bullae - and found no false positive diagnoses in patients with no or mild emphysema. The correct diagnosis of emphysema was made in more than $95 \%$ of patients with moderate and severe emphysema.

A $90 \%$ correct diagnosis of the presence or absence of emphysema was made by Sutinen et al (93) using the criterisı of overinflation. Nicklaus et al (94) studied inter-and intra-observer variations of five radiological signs of emphysema. The sign with the least false positives (4\%) and the most true positives $(94 \%$ ) was flattening of the diaphragm on posteroanterior radiographs. They found that the reader's opinion on subjective integration of the observations was even better; there were $4 \%$ false positives, and $98 \%$ of cases of severe emphysema were correctly recognized. The presence of two or more of the radiological variables recognized all patients with severe emphysema and produced 10\% false positives. Reduction of the pulmonary arterial vasculature in the outer half of the lung fields was the sign that recognized the smallest proportion of patients with severe emphysema $(54 \%)$, and there was considerable interobserver variation. One observer correlated this sign reasonably well with emphysema, but two did badly. Others (95) also found that depression of the diaphragm indicated severity of emphysema better than narrowing of the midlung vessels. Neither these nor other assessed signs were very good, and all signs were imprecise in the presence of tuberculous infiltrates. Boushy et al (96) found abnormal peripheral arterial deficiency in 23 of 27 patients with severe emphysema and overinflation in 25 . Overinflation was found in 10 of 33 patients with no or mild emphysema, and two of these also had arterial deficiency.

I have been involved in two studies of radiological/morphological correlations in patients with CAO $(97,98)$. In the first (97), the arterial deficiency pattern was present in $65 \%$ of patients with the severest emphysema and was present slightly less frequently in patients with moderate emphysema; no false positive diagnoses were made. The paper introduced the concept of increased marking emphysema, a condition in which the vascular markings were not only increased in size, but also in frequency. It appeared that this category represented cor pulmonale. irrespective of the amounts of emphysema, since various clinical, radiological and morphological signs of righ ventricular hypertrophy were frequently found in increased marking emphysema. irrespective of the severity of emphysemit.

All the studies referred to above were made on populafions heavily biased towards patients with severe CAO and patients who had ante mortem tests of pulmonary function. We therefore studied 698 patients who had both ante mortem chest radiographs and paper-mounted whole-lung sections made at autopsy (98). Although there was still a bias towards patients with significant $\mathrm{CAO}$ and emphysema, more than half were free from emphysema or had trivial emphysema. A subgroup of 257 patients was also analyzed that met the criteria of having good quality posteroanterior and lateral radiographs and no morphological or radiological disease likely to interfere with the diagnosis of emphysema (A) cases). The radiological diagnosis of emphysema was based on arterial deficiency, and emphysema severity grade (ESG) was assessed from the whole lung sections. Emphysema was seldom diagnosed in patients with no (ESG1) or trivial em physema (ESG2), and the diagnosis was made with increasing frequency as emphysema became more severe. In the group with the worst emphysema (ESG9) emphysema was recognized radiologically in $41 \%$ of all cases and $67 \%$ of $\mathrm{Al}$ cases. Emphysema was recognized more frequently in patients with $\mathrm{CAO}$ in each ESG group although the radiologist involved was unaware of the clinical features. As emphysema got worse, lung length and the size of the retrosternal space increased and the diaphragm was lower. Lung width and heart size were not related to the amount of emphysema. Considerable overlap was found in the value of the measured variables between patients ranked according to ESG. and it was not possible to develop combinations of them that were more accurate than the diagnosis of emphysema made on the basis of alterations of the pulmonary vasculature. The defect of the study was that absolute measurements were made; liall subjects had larger dimensions than short subjects.

Some authors have suggested that only PLE (92), and? others that only CLE (95), produce radiological abnormalities, but most other observers have found that both types show evidence of radiological emphysema $(93,94,97,98)$. We found that emphysema localized radiologically to the upper zones of the lung was more frequently CLE in type, and emphysema localized to the lower zones was most licquently PLE (98).

It is apparent from the ahove review lhat the evidence conceming the relationship between emphysema and the chest radiograph is conflicting, with some observers finding very good relations between the severity of emphysema and the radiological diagnosis, and others not. However, the paradox is that even those who found good correlations have used different radiological criteria to reach their conclusions. Hyperinflation appears to be present in a higher proportion of cases with severe emphysema than the arterial deficiency pattern is, but produces false positives, which occur only rarely when arterial deficiency is used as a criterion. Arterial deficiency appears to be a difficult sign to recognize and varies considerably between observers; indeed, the exact criteria for the recognition of arterial deficiency have never been agreed on. 


\section{Significance of the radiological diagnosis of emphysema}

Some thought should be given to what is meant by the radiological diagnosis of emphysema, and what results are interpreted as false positive or as false negative. A positive diagnosis of emphysema radiologically presumably does not mean that emphysema is present morphologically. Not many lungs are entirely free from emphysema pathologically, and the accuracy of the radiological diagnosis would be quite good if emphysema were diagnosed on every chest radiograph. Alternatively, it may be thought that the radiological diagnosis of emphysema implies that severe emphysema is present. Therefore, are patients with mild or moderate emphysema diagnosed as having emphysema radiologically really false positives? What is required is some sort of quantitative approach to the radiological diagnosis - is it absent, mild, moderate, or severe? Pathologically, emphysema may be absent or present. Thus, a true negative occurs when emphysema is thought to be absent both pathologically and radiologically, and a false positive occurs when emphysema of any severity is diagnosed radiologically and absent pathologically.

An approach to severity could be based on the number of radiological signs that are present. Lohela et al (99) assessed 88 patients whose lungs were examined post mortem, using the criteria of Sutinen et al (93) and Nicklaus et al (94). They provide data concerning the sensitivity, specificity and accuracy for the diagnosis of more than trivial emphysema (PG greater than 10) and mild and moderate emphysema (PG greater than 20). Another way of analyzing their data is to calculate the mean number of radiological signs present; this was 0.98 in no or trivial emphysema (PG 5 or less), 2.13 in mild emphysema (PG 10 to 30), 2.80 in moderate emphysema (PG 30 to 50) and 3.13 in severe emphysema (PG 60 or above). The authors came to the conclusion that the radiological diagnosis of emphysema could be made with reasonable accuracy using mainly the criterion of overinflation. Thurlbeck and Simon (98) did not find an increase in width of the lung with increasing emphysema (ie, that the main expansion of the lung is in the axial plane; interestingly, the lack of overinflation in the lateral plane, but overinflation in the posteroanterior plane, accounts for the 'barrel-chest' of emphysema), thus suggesting that flattening of the diaphragm is likely to be important. Pratt (100) has been a staunch advocate of 'overinflation' being the most significant criterion of emphysema, and has shown a good correlation between the severity of emphysema and increased lung volume. This may be the great value of chest radiographs (see below).

\section{Computed tomography}

CT scanning was first used in the diagnosis of emphysema in 1982 (101) in a group of 19 volunteers and 53 patients, 29 of whom had irreversible airflow obstruction. Patients diagnosed as having emphysema on chest radiographs using standard criteria showed pruning of small pulmonary vessels, distortion of vessels around areas of lower attenuation value,
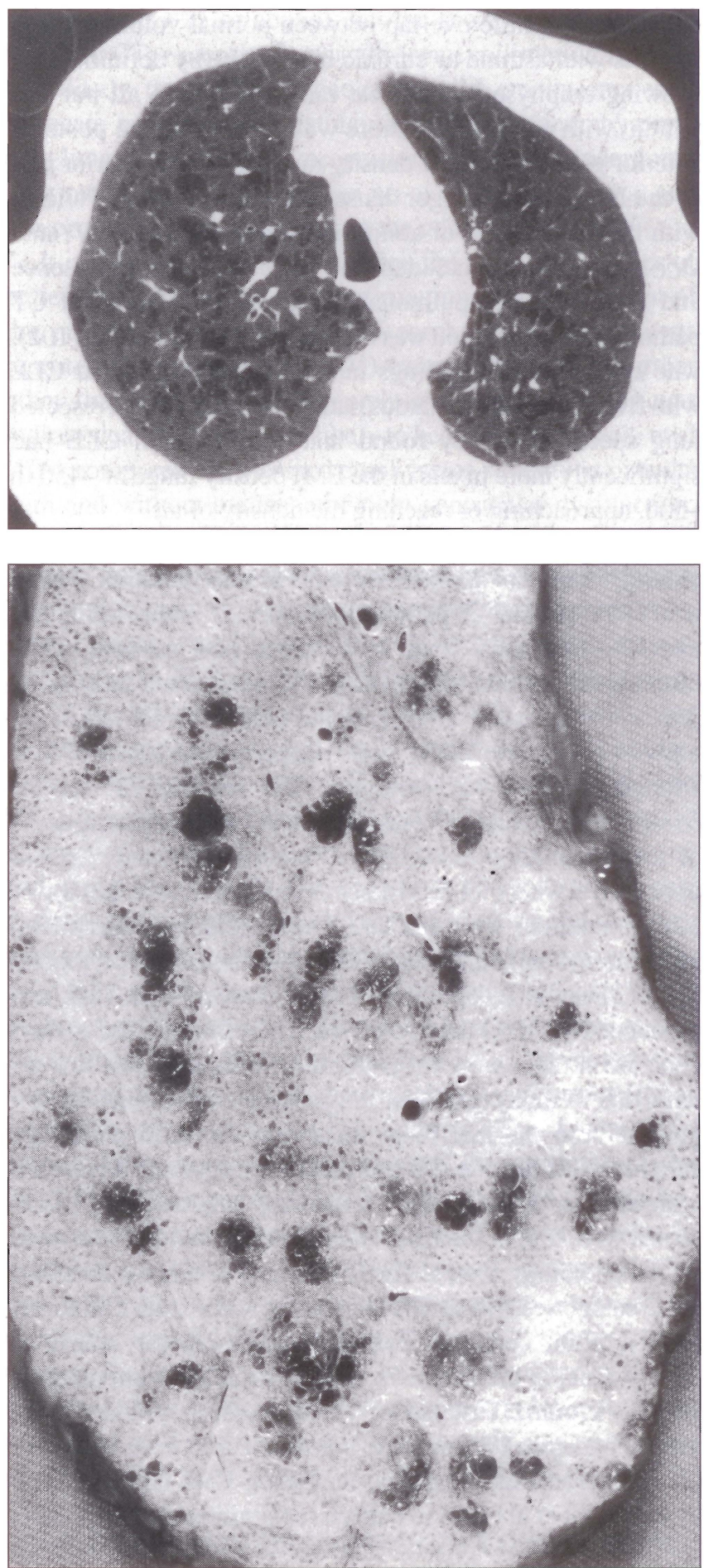

Figure 5) (Above) High resolution computerized tomographic (1.5 mm collimation, high spacial frequency algorithm) at the level of the aortic arch. Localized areas of low attenuation measuring 2 to $5 \mathrm{~mm}$ in diameter are present in both upper lobes (courtesy Dr N Müller). (Below) Corresponding slice of Bouin's fixed lung showing centrilobular emphysematous spaces (courtesy Dr R Miller)

and enlargement of the main pulmonary arteries on CT scans. Attenuation correlated well with diminished pulmonary vessels (Spearman rank correlation $r_{\mathrm{S}}=0.76$ ). Lowest mean attenuation numbers were found in emphysematous patients 
and there wats little overlap between normal volunteers and patients with asthma or chronic bronchitis (by definition not showing emphysema on chest radiographs). In all but one patient with emphysema there was reversal of the posteroanterior gradient of EMI density numbers (the posterior part of the lung was no longer denser than the anterior). Patients with high CT scores of abnormality had a lower FEV $F_{I}$ and DCO. The authors concluded that "CT can detect the presence and distribution of pulmonary emphysema". The first CT pathological correlation was reported by Hayhurst et al (102), who compared CT findings in six patients with mild CLE with five nonemphysematous patients as assessed on resected lung specimens. They found that patients with CLE had significantly more pixels in the EMI density range of -450 to $-50($ ), approaching or reaching the density of air.

Subsequent studies have shown fairly consistent results, although there are some differences in interpretation. Foster et al (103) studied 25 patients who had CT scans during life and who had lungs fixed by inflation post mortem. They found good correlations between CT assessment of emphysema and the extent of CLE found pathologically, with the highest correlation being with nonperipheral areas of low attenuation $\left(r_{s}=0.84\right)$, followed by pruning of vessels $\left(r_{\mathrm{s}}=0.73\right)$, distortion of vessels $\left(\mathrm{r}_{\mathrm{s}}=0.68\right)$ and peripheral areas of low attenuation $\left(\mathrm{r}_{\mathrm{s}}=0.63\right)$ (all values given here are for upper lobes where CLE is likely to be more severe, but lower lobe correlations were similar). The correlation with density gradient was not significant. The criterion of nonperipheral low attenuation recognized 13 of 1.5 patients with CLE and produced two of 10 false positives. The authors noted in their conclusion that using the criterion of nonperipheral low attenuation "emphysematous lungs were consistently distinguished from normal lungs except in the mild pathology subgroup". When the CT and pathology findings were each compared as 'none', 'mild', 'moderate' and 'severe', 13 CT scores were higher than, seven lower than, and five the same ats, the pathology scores. The assessment of emphysema into these categories was different pathologically from CT. In the former, point counting was used to assess the extent of emphysema; in the latter, the overall severity of attenuation, vascular pruning, vascular dilation and density gradient were used. Conccptually, this paper marked a shift from objective CT measurements of emphysema using EMI numbers used by Hayhurst et al (102) to pattern recognition of emphysema by $\mathrm{CT}$.

In the first of five papers from Vancouver, using six patients with emphysemal whose lungs were cut in the same plane as the CT scans, Bergin et al (104) noted that the destruction seen on CT in CLE was distinctly different from that seen in PLE, and that distal acinar and irregular emphysema could be demonstrated. In CLE, the changes were upper zonal with irregular, punctate or confiuent zones of low density interspersed with normal lung (Figure 5); vascular pruning was only seen in severe examples, and vascular branching was less than $80^{\circ}$. PLE was lower zonal with diffusc low density and little normal lung, vascular pruning was more obvious and valsculat branching was often greater than $80^{\circ}$. Subsequently, Bergin et al (26) reported 32 patients who had lungs or lobes resected and were assessed by severity of emphysema using a modification of the PG method. Using low attenuation and vascular pruning, CT was assessed by three radiologists as 'absent' $(0)$, less than $25 \%$ involvement (1), between 25 and $50 \%$ (2), between 50 and $75 \%$ (3), and greater than $75 \%$ involvement (4) on all relevant CT slices, and a score was expressed as a percentage of maximum. Observer 3 found correlation coefficients between CT and pathological emphysema of 0.71 for lobes and 0.88 for lungs. In all instances, CT scanning scores were lower than pathology scores. Pathology scores correlated well with the FEV .

Miller et al (23) examined 38 resected lobes or lungs (Figure 5) and used both the PG and the extent and severity of emphysema on slices cut in the plane of the CT sean (grid method). CT was measured by extent and severity similar to the grid method. The authors found good correlations between the panel and CT scores $(\mathrm{r}=0.81$ for $10 \mathrm{~mm}$ collimation scans and $\mathrm{r}=0.85$ for $1.5 \mathrm{~mm}$ collimation scans). Similar good correlations were found between $\mathrm{CT}$ and the grid score $(\mathrm{r}=0.70$ for $10 \mathrm{~mm}$ collimation scan, $\mathrm{r}=0.72$ for $1.5 \mathrm{~mm}$ collimation scans). CT scans consistently underestimated the grid score, and the correlation was almost nonexistent in grid scores below 2 (equivalent to PG 25). CT also underestimated the extent of emphysema. Four patients with mild CLE and two patients with mild to moderate PLE were not recognized by CT (out of 33 patients with emphysema). One patient with no emphysema was diagnosed as having emphysema on CT. Four cases with mild and moderate distal acinar and/or irregular emphysema were correctly recognized by CT. The authors concluded that "CT consistently underestimated the extent of centriacinar and panacinar emphysema because most of the lesions less than $0.5 \mathrm{~cm}$ in diameter were missed".

As part of a study on capillary blood volume in emphysema, Morrison et al (24) examined 55 patients with resected lobes or lungs in whom 31 had CT. This study showed generally similar results to the previous one - when slices were compared, the scores correlated well $(\mathrm{r}=0.91)$ but $\mathrm{CT}$ severity was consistently underestimated and below PG 20 no correlation existed. Finally, the Vancouver General Hospital group considered the issue of CT scanning in PLE (105). Ten patients with PLE (severe in four patients who had $\alpha_{\mid \text {AT }}$ deficiency and underwent lung transplants) were compared with five normal individuals using conventional $\mathrm{CT}$ and high resolution CT. Emphysema was assessed pathologically using the PG method and the extent of emphysema using CT. Three (with scores of PG 5, 15 and 25) of nine patients with emphysema were missed on conventional $\mathrm{CT}$ by both the radiological observers, and a fourth case (PG I0) was missed by one observer. On high resolution $\mathrm{CT}$ only two cases (scores of PG 5 and 15) were missed by both observers. Both radiological observers underestimated the extent of PLE using conventional CT (slope 0.47 ) but less so on high resolution CT (slope 0.67), and in both instances significant correlations were found ( $\mathrm{r}=0.90$ and 0.96 , respectively). One 
patient of two without emphysema was diagnosed as having emphysema using high resolution CT, and one of five was diagnosed as having emphysema by one observer using conventional $\mathrm{CT}$. The observers noted that high resolution $\mathrm{CT}$ allowed improved identification of structural abnormalities.

In a return to using EMI numbers rather than pattern recognition, Gould et al (27) expressed CT as the EMI unit defining the lowest fifth percentile of the distribution of CT numbers and compared this with the mean value of AWUV (a measurement that reflects both emphysema and airspace enlargement) of the worst five fields, ie, the worst were compared with the worst. This showed a correlation of $r=0.77$. Both EMI numbers and AWUV values are expressed in various ways, and lower correlations exist between values other than those chosen by the authors.

The paper that indicates the most accurate CT diagnosis of emphysema came from Japan (14). This study used 42 pitients whose lobes were resected. Intravenous contrast was used. The investigators estimated emphysema using the PG method on both CT and resected lobes; five slices per lobe were measured, and they compared $1 \mathrm{~mm}$ and $5 \mathrm{~mm}$ collimation scans. The CT criteria were zones of attenuation and 'vascular disruption'. They found correlations of +0.68 for I mm collimation scans and +0.76 for $5 \mathrm{~mm}$ collimation scans. The $5 \mathrm{~mm}$ collimation scans consistently underestimated the severity of emphysema found pathologically, but the $1 \mathrm{~mm}$ scans did not. The average emphysema score was 22.1 for $1 \mathrm{~mm}$ collimation and 23.2 by pathology in the resected lobes. Significant inter- and intra-observer variations were noted by the three observers, but their average score was used. What is surprising about this study, which included 14 nonsmokers of 42 subjects, is that there were no patients with either a CT or pathology score of less than 10 . The authors attributed this to the lact that they examined five slices by both CT and pathology and thus were likely to find minimal grades of emphysema. It seems unlikely that this is the whole explanation since their experience is unique. More to the point it is clear from inspection of the data that there is no correlation in lungs with pathology scores below 20 . Correlations of their datal can be calculated, and these show $r^{2}$ values of 0.13 for $1 \mathrm{~mm}$ scans and 0.00 for $5 \mathrm{~mm}$ collimation scans. These findings explain the low correlations found in all cases for both scans, despite apparently good slopes comparing CT with pathology. The group of lungs with $\mathrm{PG}$ less than 20 cannot be ignored since it is likely to include lungs that most pathologists would consider free from emphysema or lungs with mild emphysema.

Finally, we should consider correlations between lungs assessed pathologically at post mortem examination with CT also done post mortem (106,107). Hruban's study (106) showed an excellent correlation $(r=0.91)$ with a slope close to 1. However, this should not be surprising since conventional post mortem radiographs also recognize emphysema very well (108).

From the above discussion. it appears that CT will recognize emphysema when pathologically emphysema is more than mild (PG 25 or above), but the scores are likely to be lower on CT, except perhaps with $1 \mathrm{~mm}$ collimation scans. It is unlikely that CT can recognize mild emphysema with adequate precision and distinguish it from nonemphysematous lungs. A substantial proportion of patients undergoing lung resection will either have no or mild enphysema, and this proportion will be higher in the general population.

It is thus appropriate to examine the use of CT studies of patients without pathology confirmation, where the point of the paper is the significance of emphysema. The patients reported by Goddard et al (10I) cannot be analyzed further other than to observe that emphysema in their cases was radiologically obvious and likely to be severe. Biernacki et al (109) compared CT assessed emphysema severity in patients with and without evidence of right ventricular dysfunction. There was no relationship between CT score (using the EMI number defining the lowest fifth percentik of the frequency distribution) and hypoxemia, pulmonary arterial pressure or cardiac index. This $\mathrm{CT}$ assessment of emphysema is reason able since the EMI number defining the lowest fifth percentile of the CT density histograms was -463 , indicating that the average patient had moderately severe and severe emphysema, in the range in which CT is likely to be accurate. The CT values correspond approximately to PG 50) to 70 found in patients in whom the same issue was investigated using pathology only (110). These authors also concluded that pathologically emphysema severity did not seperate patients with evidence of right ventricular hypertrophy and dysfunction. Instead they found that patients with right ventricular dysfunction had greater evidence of airway narrowing and lower ventilatory drive. On the other hand, the conclusion reached by Gelb et al (111) that "emphysema does not appear to be primarily responsible for expiratory flow limitation in chronic obstructive pulmonary disease" does not appear to be valid. From their paper, 26 of 51 patients had a CT emphysema score of 20 or less (in the range CT has little value in assessing emphysema). This affects the key interpretation of their paper. It is worth noting that these patients are described as having severe CAO, yet their average CT score of 2.3 is close to the average score of 22 found by Kuwano et al who described their patients as having mild emphysema. Also, more than $50 \%$ of their patients were female, and only seven of 56 had chronic bronchitis.

\section{THE DIAGNOSIS OF EMPHYSEMA DURING LIFE}

There seems to be little doubt that DCO is the best single predictor of emphysema during life. Early evidence hats been previously reviewed (30). Since then this has been confirmed in several studies in both mild and severe emphysema with correlations between the DCO and emphysema being generally in the region of 0.5 to $0.6(25,26,44,47,48)$. The only exception was McLean et al ( 112 ) who found a poor correlation with 'macroscopic emphysema', but there were significant correlations with AWUV and the number of centrilobular lesions. The steady state diffusing capacity may not have a significant advantage over the single breath method $(14,24)$. 


\begin{tabular}{ll} 
Glossary of terms \\
\hline$\alpha_{1} A T$ & $\alpha_{1}$ antitrypsin \\
AWUV & Airspace wall per unit volume \\
CAO & Chronic airway obsruction \\
CLE & Centrilobular emphysema \\
CT & Computerized tomography \\
DCO & Diffusing capacity for carbon monoxide \\
DI & Destructive index \\
ESG & Emphysema severity grade \\
FEV & Forced expiratory volume \\
ISA & Alveolar surface area \\
IWD & Interalveolar wall distance \\
Lm & Mean linear intercept \\
PG & Panel grade \\
PL & Transpuimonary pressure \\
PLE & Panlobular (panacinar) emphysema \\
RV & Residual volume \\
SEM & Scanning electron microscopy \\
TLC & Total lung capacity \\
V 30 & Lung volume at 30 cm $\mathrm{H}_{2} O$ \\
&
\end{tabular}

TLC was initially not well related to the severity of cmphysema (30). This is not surprising since TLC was generally measured by helium dilution. As also indicated, the increase in lung volume with emphysema is well recognized and has been emphasized by Pratt (100). More recent studies, using body plethysmography, have found a significant correlations between emphysema and TLC in some studies (44) but not in others $(14,27,47)$.

We have repeatedly stressed the importance of an integrated approach to the diagnosis of emphysema $(30,44,113)$, and by emphysema we mean as it is defined by the Ciba symposium or the National Institutes of Health. At the simple clinical level, the history is significant. The more the patient is unusual clinically, the less likely is emphysema to be present. An absence of a history of cigarette smoking and young age make emphysema unlikely to be present. A 50- or 60)-year-old cigarette smoker with chronic bronchitis is likely to have emphysema. Physical examination is not very helpful except when emphysema is severe and the physical signs are very obvious. Chest radiographs should emphasize overinflation, low diaphragm position and lung volumes, and if added evidence of emphysema (such as irregular radiolucencies) is present this should be regarded as a bonus.

TLC can be adequately measured by planimetry from standard chest films (114) and simple programs can be written to determine TLC from the chest radiograph. All patients with suspected CAO have chest films; it follows that care should be taken that these are at full inspiration. Determining TLC from a chest radiograph is simpler, quicker and cheaper than from a body plethysmograph. FEV I has stood the test of time, and expressed as a percentage of predicted or as a percentage of forced vital capacity, is not only an indicator of disability but also, in the appropriate circumstances, provides some indication of the severity of emphysema. Thus, the simple steps of history taking, spirometry, chest radiography and a sniff of carbon monoxide go a long way towards determining the severity of emphysema in living subjects. The above applies particularly to patients seen in the clinic.
In patients with milder $\mathrm{CAO}$, the diffusing capacity plays a more important role and CT may be significant.

Why be concerned about the presence or severity of emphysema? First, because it is there and it is appropriate to try and make as precise a diagnosis as possible in any disease. Secondly, emphysema may become amenable to treatment. Antiprotease treatment is well recognized in alpha-1-antiprotease deficiency, but cheaper and more effective pharmaceuticals may become available in the futurc.

\section{CONCLUSION}

I have reviewed certain aspects of the pathology of em physema with a view to drawing readers' attention to its continuing significance and importance. Definitions are needed for precision; recognition and measurement are essential requirements for the understanding of clinicopathologic correlations. Emphysema cannot be considered in isolation from airway disease which is not reviewed here. It is obviously possible for a patient to suffer from severe or even fatal CAO in the absence of emphysema. The best examples are easily recognized in nonsmokers such as in rheumatoid bronchiolitis and in other uncommon conditions (115). Chronic bronchitis by itself does not appear to be an important cause of $\mathrm{CAO}$, but the role of bronchial wall thickening has not been thoroughly investigated. After all, a major hypothesis of airflow obstruction in asthma is related to bronchial wall thickening (116) and bronchial wall thickening does occur in chronic bronchitis (117).

The relationship between emphysema and flow obstruction should be more carefully analyzed. Expiratory flow obstruction may be due to emphysema caused by loss of radial attachments and bronchiolar distortion; it may also be due to associated smoking-related bronchiolitis. Emphysema can only be considered in isolation from bronchiolar disease in nonsmoking patients with $\alpha_{1} \mathrm{AT}$ deficiency. The presence of fibrosis in three forms of emphysema - CLE, distal acinar and irregular - emphasizes the role of inflammation and scarring in its pathogenesis. In PLE there is no such evidence but there appears to be loss of elastic tissue alone. These observations require explanation. Diminished elastin in CLE, distal acinar and irregular emphysema reflect the inevitable effect of inflammation which destroys elastin.

Is there further work to be done? Of course. Our knowledge of control of elastin and collagen synthesis and catabolism are rudimentary. The role of proteases is not yet properly explored. Proteoglycans have been almost entirely neglected in emphysema. The powerful tools of molecular biology and molecular genetics need to be applied, not for their own sake but for the sake of understanding an important and common condition. The principles of inflammation in general are relatively well explored. It seems unlikely that these principles are different in the lung than in other organs and it is likely that the way that lungs, and their constituent parts, respond to inflammation is more important.

The easiest approach is in experimental animals, but consideration must still be given to human studies. Carefully thought out clinicopathological studies will provide further 
information. Just because the techniques are simple does not mean that they cannot contribute further, nor that they should be applied nonrigorously. Surgically resected lungs are readily available and what is needed are more complete and thorough studies. Lungs rather than lobes need to be investigated. The lungs should be carefully examined and as much information obtained from them as possible. The amount and type of emphysema needs to be properly assessed, and both gross and microscopic examination is necessary. A proper record such as paper-mounted whole lung sections should be kept. Recognition and measurement of emphysema alone are not adequate, but new ideas and measurements, such as the DI, AWUV and alveolar attachments should be implemented. It should be recognized that DI and AWUV or IWD include both emphysema and other components (breaks in

\section{REFERENCES}

1. Leopold JG, Gough J. The centrilobular form of hypertrophic pulmonary emphysema and its relation to chronic bronchitis. Thorax 1957; 12:219-35.

2. McLean KH. The pathogenesis of pulmonary emphysema. Am J Med 1957;25:62-74,

3. Ciba Guest Symposium Report: Terminology, definitions, and classification of chronic pulmonary emphysema and related conditions. Thorax 1959;14:286-99.

4. Pickering GA. Hyperpiesis: High blood pressure without evident cause: Essential hypertension. Br Med J 1965;2:959-86.

5. Boren HG. Alveolar fenestrae. Relationship to the pathology and pathogenesis of pulmonary emphysema. Am Rev Respir Dis 1962;85:328-44.

6. Nagai A, Inano H, Matsuba K, Thurlbeck WM. Scanning electron-microscopic observations of emphysema in the human. Morphometric and correlative studies. Am Rev Respir Dis 1994. (In press)

7. Nagai A, Thurlbeck WM. Scanning electron microscopic observations of emphysema in humans. A descriptive study. Am Rev Respir Dis 1991;144:901-8.

8. Cosio MG, Shiner RJ, Saetta M, et al. Alveolar fenestrae in smokers. Relationship with light microscopic and functional abnormalities. Am Rev Respir Dis 1986;133:126-31.

9. Thurlbeck WM. Internal surface area and other measurements in emphysema. Thorax 1967;22:483-96.

10. Saetta M, Shiner RJ, Angus GE, et al. Destructive index: A measurement of lung parenchymal destruction in smokers. Am Rev Respir Dis 1985;131:764-9.

11. Eidelman, Ghezzo H, Kim WD, Cosio MG. The destructive index and early lung destruction in smokers. Am Rev Respir Dis 1991;144:156-9.

12. Saito K, Cagel P, Berend N, Thurtbeck WM. The "destructive index" in nonemphysematous and emphysematous lungs. Am Rev Respir Dis 1989;139:308-12.

13. Matsuba K, Ideda T, Nagai A, Thurlbeck WM. The National Institutes of Health Intermittent Postive Pressure trial: Pathology studies. IV. The destructive index. Am Rev Respir Dis 1989;139: 1439-45.

14. Kuwano K, Matsuba K, Ikeda T, et al. The diagnosis of mild emphysema. Correlation of computed tomography and pathology scores. Am Rev Respir Dis 1990;141:169-78.

15. Dunnill MS. Quantitative methods in the study of pulmonary pathology. Thorax 1962;17:320-8.

16. Dunnill MS. Evaluation of a simple method of sampling the lung for quantitative histological analysis. Thorax 1964;19:443-8.

17. Weibel ER. Morphometry of the Human Lung. Heidelberg: Springer Verlag, 1963. the alveolar wall in DI and airspace enlargement in AWUV and IWD) that may be significant. Airway lesions need to be quantitated and not just described qualitatively ('semiquantitatively' is the euphemism). Techniques need to be developed for processing the lungs so that established newer technolo. gies can be used. The way the lung responds to inflammation should be investigated, as should biochemical abnormalities. Lungs should be examined functionally and, in particular, elastic properties of the lung should be thoroughly investigated. Post mortem studies of lungs examined functionally during life are too difficult to be practicable. Relatively few functional studies have been performed on post mortem derived lungs. Surgically excised lungs have also shown promise. What is needed are more complete studies. We are not at the end, only at the beginning of the end.

18. Underwood EE. Quantitative Sterology. Reading: Addison-Wesley Publishing Co, 1970.

19. Kida K. Utsuyama M, Takizawa T, Thurlbeck WM. Changes in lung morphologic features and elasticity caused by streptozotocin-induced diabetes mellitus in growing rats. Am Rev Respir Dis 1983;128:125-31.

20. Kawakami M, Paul JL, Thurlbeck WM. The effect of age on lung structure in male BALB/cNNia inbred mice. Am J Anat 1984;170:1-21.

21. Gillooly M, Lamb D. Airspace size in lungs of lifelong non-smokers. The effect of age and sex. Thorax 1993;43:339-441.

22. Gillooly M, Lamb D. Microscopic emphysema in relation to age and smoking habit. Thorax 1993;48:49I-5.

23. Miller RR, Müller N, Vidal S, Morrison NJ, Staples CA. Limitation of computed tomography in the assessment of emphysema. Am Rev Respir Dis 1989;139:980-3.

24. Morrison NJ, Abboud RT, Müller NL, et al. Pulmonary capillary blood volume in emphysema. Am Rev Respir Dis 1990;141:53-61.

25. Berend N, Woolcock AJ, Marlin GE. Correlation between the function and structure of the lung in smokers. Am Rev Respir Dis 1979;1 19:695-705.

26. Bergin C, Müller N, Nichols DM, et al. The diagnosis of emphysema. A computed tomographic-pathologic correlation. Am Rev Respir Dis 1986;133:541-6.

27. Gould GA, MacNee W, McLean A, et al. CT measurements of lung density in life can quantitate distal airspace enlargement an essential defining feature of human emphysema. Am Rev Respir Dis 1988;137:380-92.

28. Snider GL, Kleinerman JL, Thurlbeck WM, Bengali ZH. The definition of emphysema. Report of a National Heart ,Lung, and Blood Institute, Division of Lung Disease Workshop. Am Rev Respir Dis 1985;132:182-3.

29. Snider GL, Lucey EC, Faris B, Jung-Legg Y, Stone PJ. Franzblau C. Cadmium chloride induced airspace enlargement with interstitial pulmonary fibrosis is not associated with destruction of lung elastin. Am Rev Respir Dis 1988;137:918-23.

30. Thurlbeck WM. Chronic airflow obstruction in lung disease. Toronto: WB Saunders Co, 1976.

31. Cardoso WV, Sekhon HS, Hyde DM, Thurbeck WM. Collagen and elastin in human pulmonary emphysema. Am Rev Respir Dis 1993;147:975-81.

32. Tetley TD. New perspectives on basic mechanisms in lung disease -6 . Protease imbalance: Its role in lung disease. Thorax 1993;48:560-5.

33. Gough J, Wentworth J. Thin sections of entire organs mounted on paper. Harvey Lecture 1957-58;53:182-5. 
34. Heard BH. A pathological study of the lungs with chronic bronchitis. Thorax 1958;13:136-49.

35. Nagai A, Yamawaki I, Thurlbeck WM, Takizawa T. Assessment of lung parenchymal destruction using routine histological sections. Am Rev Respir Dis 1989;139:3 [ 3-9.

36. Anderson AE Jr, Foraker AG. Relative dimensions of bronchioles and parenchymal spaces in lungs from normal subjects and emphysematous patients. Am J Med 1962:32:218-28.

37. Pratt PC, Haque A. Klugh GA. Correlation of postmortem function and structure in normal and emphysematous lungs. Am Rev Respir Dis 1961;83:856-65.

38. Saetta M, Ghezzo H, Kim WD, et al. Loss of alveolar attachments in smokers. A morphometric correlate of lung function impairment. Am Rev Respir Dis 1985;132:894-900.

39. Verbeken EK, Cauberghs M, Mertens I, Clement J, Lauweryns JM, Van de Woestijne KP. The senile lung. Comparison with normal and emphysematous lungs. I. Structural aspects. Chest 1992;101:793-9.

40. Willems LNA, Kramps JA, Stijnen T, Sterk PJ, Weening JJ, Dijkman JH. Relationship between small airway disease and parenchymal destruction in surgical lung specimens. Thorax 1990;45:89-94.

41. Wright JL, Hobson JE, Wiggs B, Pare PD, Hogg JC. Airway inflammation and peribronchiolar attachments in the lungs of nonsmokers, current, and ex-smokers. Lung 1988;166:277-86.

42. Petty TL, Silvers GW, Stanford RE. Radial traction and small airways disease in excised human lungs. Am Rev Respir Dis 1986;133:132-5.

43. Nagai A, Yamawaki I, Takizawa T, Thurlbeck WM. Alveolar attachments in emphysema of human lungs. Am Rev Respir Dis 1991;144:888-91.

44. West WW, Nagai A, Hodgkin JE, Thurlbeck WM. The National Institutes of Health Intermittent Positive Pressure trial - Pathology studies. III. The diagnosis of emphysema. Am Rev Respir Dis 1987;135:123-9.

45. Nagai A, West WW, Thurlbeck WM. The National Institutes of Health Intermittent Positive Pressure Breathing Trial: Pathology Studies II. Correlation between morphologic tindings, clinical findings and evidence of expiratory air-flow obstruction. Am Rev Respir Dis 1985;132:946-53.

46. Bergin C, Müller N, Nichols DM, et al. The diagnosis of emphysema. A computed tomographic-pathologic correlation. Am Rev Respir Dis 1986;133:541-6.

47. Morrison NJ, Abboud RT, Ramadan F, et al. Comparison of single breath carbon monoxide diffusing capacity and pressure-volume curves in detecting emphysema. Am Rev Respir Dis 1989;139:1179-87.

48. Pare P. Brooks A, Bates J, et al. Exponental analysis of the lung pressure-volume curve as a predictor of pulmonary emphysema. Am Rev Respir Dis 1982;126:54-61

49. Nagai A, West WW, Paul JL, Thurlbeck WM. The National Institutes of Health Intermittent Positive Pressure Breathing trial. I. Interrelationship between morphologic lesions. Am Rev Respir Dis 1985;132:937-45.

50. Wilson AG, Massarella GR, Pride NB. Elastic properties of airways in human lungs postmortem. Am Rev Respir Dis 1974;110:716-29.

51. Lamb D, McLean A, Gillooly N, Warren PM, Gould GA. MacNee W. Relationship between distal airspace size, bronchiolar attachments, and lung function. Thorax I993;48: 1012-7.

52. Thurlbeck WM. Measurement of pulmonary emphysema. Am Rev Respir Dis 1967;95:752-64

53. Thurlbeck WM, Anderson AE Jr, Janis M, et al. A co-operative study of certain measurements of emphysema. Am Rev Respir Dis 1968;98:217-28

54. Mitchell RS, Vincent TN, Ryan S, Filley GF. Chronic: obstructive bronchopulmonary disease. IV. The clinical and physiological differentiation of chronic bronchitis and emphysema. Am J Med Sci 1964;247:513-21.

55. Heard BE, Izukawa T. Pulmonary emphysema in fifty consecutive male autopsies in London. J Pathol Bacteriol 1964;88:425-31.

56. Sweet HC, Wyatt JP, Kinsella PW. Correlation of Iung macrosections with pulmonary function in emphysema. Am J Med 1960:29:277-81.

57. Anderson JA, Dunnill MS. Observations on the estimation of the quantity of emphysema in the lungs by the point sampling method. Thorax 1965;20:462-6.

58. Thurlbeck WM, Dunnill MS, Hartung W, Heard BE, Heppleston AG, Ryder RC. A comparison of three methoits of measuring emphysema. Human Pathol 1970;1:215-26.

59. Thurlbeck WM. The incidence of pulmonary emphysema: With observations on the relative incidence and spatial distribution of various types of emphysema. Am Rev Respir Dis 1963;87:206-15.

60. Ryder RC, Thurlbeck WM, Gough J. A study of interobserver variation in the assessment of emphysema in paper-mounted whole lung sections. Am Rev Respir Dis 1969;99:354-64.

61. Thurlbeck WM, Ryder RC, Sternby N. A comparative study of the severity of emphysema in necropsy population in three different countries. Am Rev Respir Dis 1974;109:239-48.

62. Petty TL, Silvers GW, Stanford RE. Mild emphysema is associated with reduced elastic recoil and increased lung size but not with air flow limitation. Am Rev Respir Dis 1987; 136:867-87.

03. Greaves IA, Colebatch HJH. Elastic behavior and structure of normal and emphysematous lungs. Am Rev Respir Dis 1980;121:127-36.

64. Petty TL, Silvers GW, Stanford RE. Functional correlations with mild and moderate emphysema in excised human lungs. Am Rev Respir Dis 1981;124:700-4.

65. Silvers GW, Petty TL, Stanford RE. Elastic recoil changes in early emphysema. Thorax 1980;35:490-5.

66. Berend N, Thurlbeck WM. Exponential analysis of the pressure-volume relationship in excised human lungs. J Appl Physiol 1982;52:838-44.

67. Cosio M, Ghezzo M, Hogg JC, et al. The relations between structural changes in small airways and pulmonary-function tests. N Engl J Med 1978;298:1277-81.

68. Wright JL, Lawson LM, Pare PD, Kennedy S, Wiggs B, Hogg JC. The detection of small airways disease. Am Rev Respir Dis 1984; 129:989-94.

69. Wright JL, Barry W, Pare PI), Hogg JC. Ranking the severity of emphysema on whole lung slices. Am Rev Respir Dis 1986;133:930-1.

70. Christie RV. The elastic properties of the emphysematous Iung and their clinical significance. J Clin Invest 1934;13:279-92.

71. Macklem PT. Airway obstruction and collateral ventilation. Physiol Rev 1971;51:368-436.

72. Hogg JC, Macklem PT, Thurlbeck WM. Site and nature of airway obstruction in chronic obstructive lung disease. $\mathrm{N}$ Engl J Med 1968;278:1355-60.

73. Hogg JC, Nepszy S, Macklem PT, Thurlbeck WM. Elastic properties of the centrilobular emphysematous space. J Clin Invest 1969;48:1306-12.

74. Niewoehner DE, Kleinerman J, Liotta L. Elastic behaviour of postmortem human lungs: Effects of aging and mild emphysema. J Appl Physiol 1975;39:943-9.

75. Thurlbeck WM. Post-mortem lung volumes. Thorax 1979; 34:735-9

76. Berend N, Skoog C, Waskiewicz L, Thurlbeck WM. Maximum volumes in excised human lungs: Effects of age, emphysema and formalin inflation. Thorax 1980;35:859-64.

77. Berend N, Skoog C, Thurlbeck WM. Pressure-volume 
characteristics of excised human lungs: Effects of sex, agc, ind emphysema. J Appl Physiol 1980;49:558-65.

78. Berend N, Skoog C, Thurlbeck WM. Lobar pressure-volume characteristics of excised human lungs. Thorax 1981;36:290-5

79. Berend N, Skoog C, Thurlbeck WM. Exponential analysis of lobar pressure-volume characteristics. Thorax 1981;36:452-5.

80. Macklem P, Eidelman D. Reexamination of the elastic properties of emphysematous lungs. Respiration 1990;57:187-92.

81. Eidelman D, Ghezzo H, Kim WD, Hyatt RE, Cosio MG Pressure-volume curves in smokers. Comparison with alpha-I-antitrypsin deficiency. Am Rev Respir Dis 1989;139:1452-8.

82. Kim WD, Eidelman DH, Izquierdo JL, Ghezzo H, Saetta MP. Cosio MG. Centrilobular and panlobular emphysema in smokers. Two distinct morphologic and functional entities. An Rev Respir Dis 1991;144:1385-90.

83. Osborne S, Hogg JC, Wright JL, Coppin C, Pare PD. Exponential analysis of the pressure-volume curve. Correlation with mean linear intercept and emphysema in human lungs. Am Rev Respir Dis 1988;137:1083-8.

84. Laros CD, Kuyper CMA. The pathogenesis of pulmonary emphysema. Respiration 1976;33:324-48.

85. Mcllroy MB, Christie RV. A postmortem study of the visco-elastic properties of the lung in emphysema. Thorax 1952; 7:295-8.

86. Ishikawa S, Fattal GA, Zylak C, Cherniack M, Wyatt JP. A post-mortem study of the viscoelastic properties of lung in emphysema (Correlation with quantitative morphometry). In: Current Research in Chronic Obstructive Lung Disease. Proceedings of the 10th Aspen Emphysema Conference. US Public Health Service Publication. 1969;325-37.

87. Haber PS, Colebatch HJ, Ng CK, Greaves IA. Alveolar size as a determinant of pulmonary distensibility in mammalian lungs. J Appl Physiol 1983;54:837-45.

88. Park SS, Janis M, Shim CS, Williams MJ Jr. Relationship of bronchitis and emphysema to altered pulmonary function. Am Rev Respir Dis 1970;102:927-36.

89. Boushy SF, Aboumrad MH, North LB, Helgason AH. Lung recoil pressure, airway resistance and forced expiratory flows related to morphologic emphyscmil. Am Rev Respir Dis 1971;104:55l-61.

90. Gelb AF, Gould WM, Wright RR, Brush JR, Nadel JA. Physiologic diagnosis of subclinical emphysema. Am Rev Respir Dis 1973;107:50-63.

91. Laws JW, Heard BE. Emphysema and the chest film: A retrospective radiological and pathological study. $\mathrm{Br} J$ Radiol 1962:35:750-61.

92. Reid L, Millard FJC. Correlations between radiological diagnosis and structural lung changes in en physema. Clin Radiol 1964;15:307-11.

93. Sutinen S, Christofordis AJ, Klugh JA, Pratt PC. Roentgenologic criteria for the recognition of non-symptonatic pulmonary emphysema. Correlation between roentgenologic findings and pulnonary pathology. Am Rev Respir Dis 1965;91:69-76.

9. Nicklaus TM, Stowell DW, Christiansen WR, Renzetti $A D$ Jr. The accuracy of the roentgenologic diagnosis of chronic pulmonary emphysema. Am Rev Respir Dis 1966;93:889-99.

95. Katsura S, Martin CJ. The roentgenologic diagnosis of anatomical emphysema. Am Rev Respir Dis 1967;96:700-6.

96. Boushy SF, Aboumrad MH, North LB, Helgason AH. Lung recoil pressure, airway resistance, and forced flows related to morphologic eniphysema. Am Rev Respir Dis 1971;104:551-61.
97. Thurlbeck WM, Henderson JA, Fraser RG, Bates DV. Chronic obstructive lung disease. A comparison between clinical, roentgenologic, functional and morphologic criteria in chronic bronchitis, emphysema, asthma, and bronchiectasis. Medicinc 1970;49:81-145

98. Thurlbeck WM, Simon G. Radiographic appearance of the chest in emphysema. Am Roentgenol 1978:1.30:429-40.

99. Lohela P, Sutinen S, Pääkkö P, Lahti R, Tienari J. Diagnosis of emphysema on chest radiographs. Fortschr Rontgenstr 1984;141:395-402.

100. Pratt PC. Role of conventional chest radiography in diagnosis and exclusion of emphysema. Am J Med 1987;82:998-1006.

I01. Goddard PR, Nicholson EM, Lazlo G, Watt I. Computed tomography in pulmonary emphysema. Clin Radiol 1982;33:379-87.

102. Hayhurst MD, Flenley DC, McLean A, el al. Diagnosis of pulmonary emphysema by computerized tomography. Lancet 1984;ii:320-2.

103. Foster WL Jr, Pratt PC, Roggli VL, Godwin JD, Halvorsen RA $\mathrm{Jr}$, Putman CE. Centrilobular emphysema: CT-pathologic correlation. Radiology 1986;159:27-32.

104. Bergin CJ, Müller NL, Miller RR. CT in the qualitative assessment of emphysema. J Thorac Imag 1986;1:94-103

105. Spouge D, Mayo JR, Cardoso W, Müller NL. Panacinar emphysema: CT and pathologic findings. J Comput Assist Tomog 1993;17:710-3.

106. Hruban RH, Meziane MA, Zerhouni EA, et al. High resolution computed tomography of inflation-fixed lungs.

Pathologic-radiologic correlation of centrilobular emphysema. Am Rev Respir Dis 1987;136:935-40.

107. Murata K, Ito H, Todo G, et al. Centrilobular lesions of the lung: Demonstration by high-resolution CT and pathologric correlation. Radiology 1986;161:641-5.

108. Sutinen S, Lohela P, Pääkö P, Lahti R. Accuracy of postmortem radiography of excised air-inflated human lungs in assessment of pulmonary emphysema. Thorax 1982;37:906-12.

1(1). Biernacki I, Gould GA, Whyte KF, Flenley DC. Pulmoniry hemodynamics, gas exchange, and the severity of emphysema as assessed by quantitative CT scan in chronic bronchitis and emphysema. Am Rev Respir Dis 1989;139:1509-15.

I 10. Jamal K, Fleetham JA, Thurlbeck WM. Cor pulmonale: Correlation with central airway lesions, peripheral airway lesions and control of breathing. Am Rev Respir Dis 1990;141:1172-7.

111. Gelb AF, Schein M, Kuei J, et al. Limited contributon of emphysema in advanced chronic obstructive pulmonary disease. Am Rev Respir Dis 1993;147:1157-61.

112. McLean A, Warren PM, Gillooly N, MacNee W, Lamb D. Microscopic and macroscopic measurement of emphysema: Relation to carbon monoxide gas transfer. Thorax 1992;47:144-9.

113. Thurlbeck WM. Chronic airllow obstruction. Correlation of structure and function. In: Chronic Obstructive Pulmonary Disease. Petty TL, ed. New York: Marcel Dekker Inc, 1985.

114. Harris TR, Pratt PC, Kilburn KH. Total lung capacily measured by roentgenograms. Am J Med 1971;50:756-63.

115. Wright JL, Cagle P, Churg A, Colhy TV, Myers J. State of the art. Diseases of the small airways. Am Rev Respir Dis 1992;146:240-62.

1 6. James AL, Pare PD, Hogg JC. The mechanics of airway narrowing in asthma. Am Rev Respir Dis 1988;139: 136-9.

1 17. Pare PD, Wiggs BR, James A, Hogg JC, Bosken C. The comparative mechanics and morphology of airways in asthma and in chronic obstructive pulmenary disease. Am Rev Respir Dis 1991:143:1 189-92. 


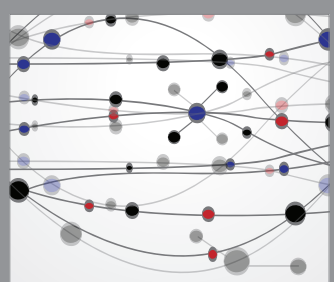

The Scientific World Journal
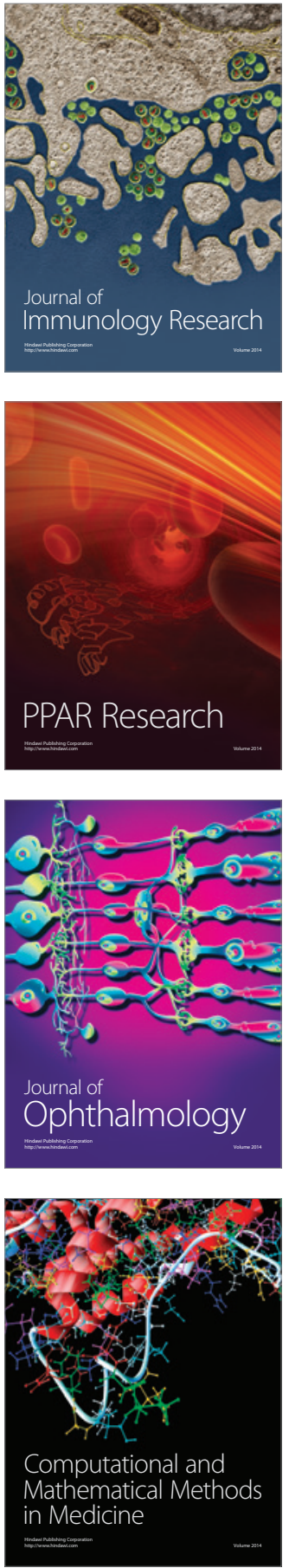

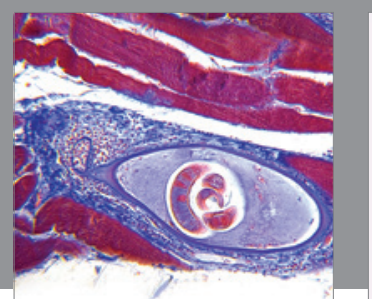

Gastroenterology Research and Practice

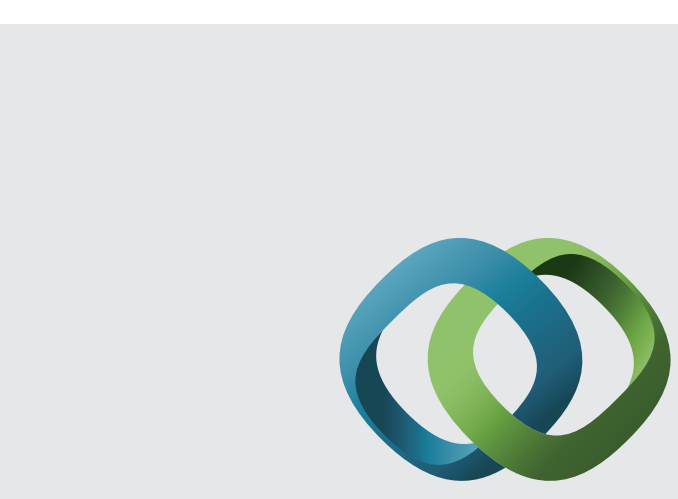

\section{Hindawi}

Submit your manuscripts at

http://www.hindawi.com
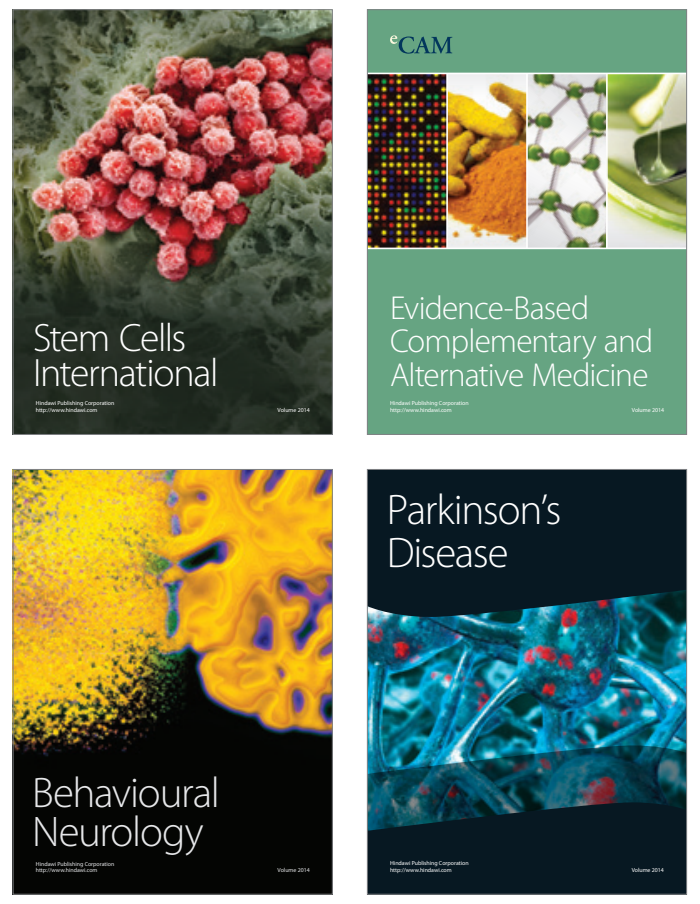
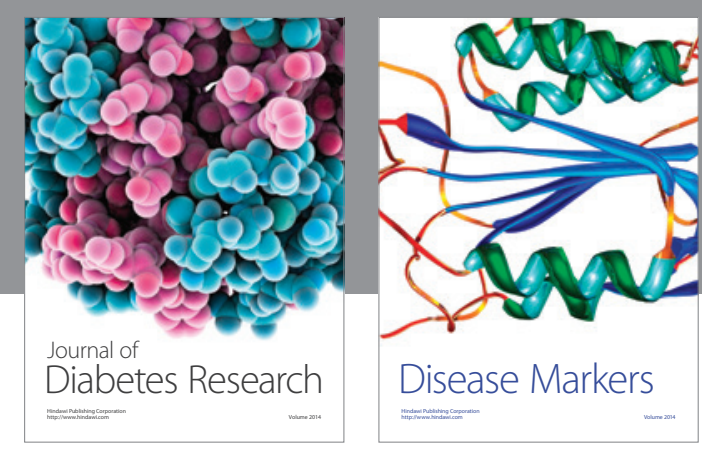

Disease Markers
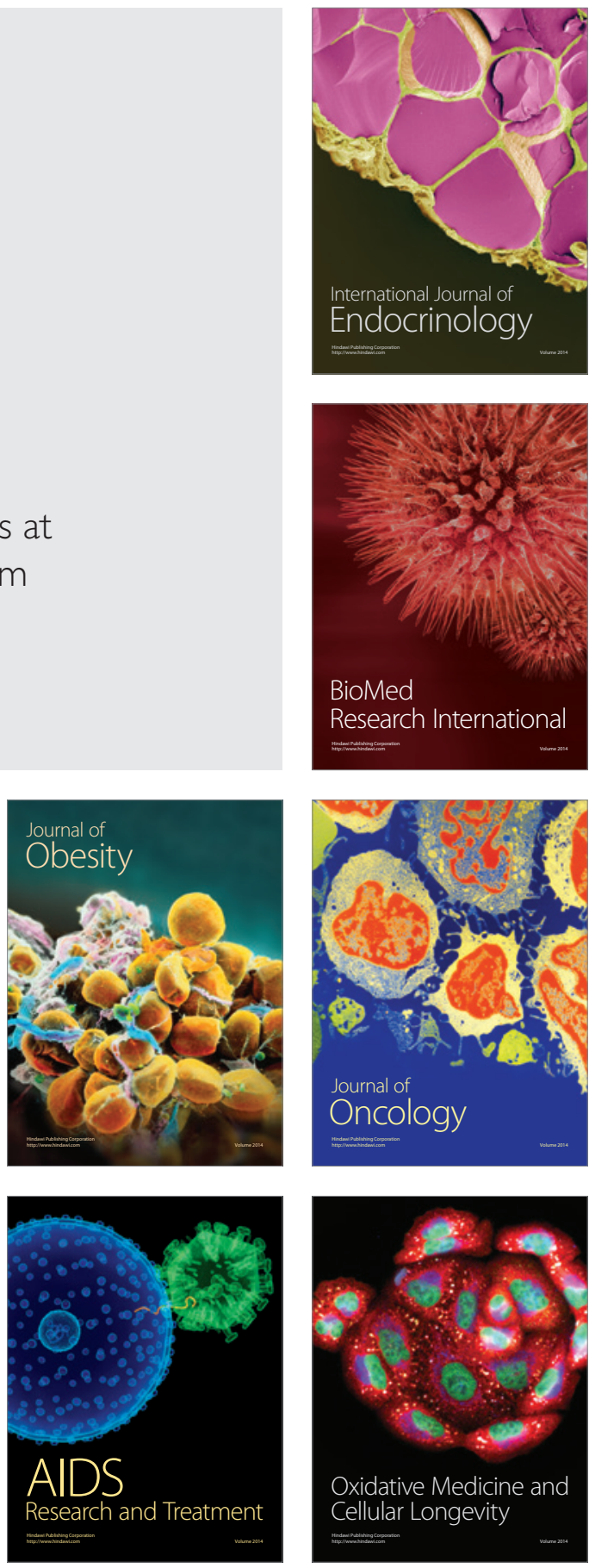